\title{
Effects of Different Biodiesel-Diesel Blend Fuel on Combustion and Emission Characteristics of a Diesel Engine
}

\author{
Yanhui Zhang ${ }^{1,2,3}$, Yunhao Zhong ${ }^{1,3}$, Jie Wang ${ }^{1,3}$, Dongli Tan ${ }^{2,3}$, Zhiqing Zhang ${ }^{1,3(1)}$ and Dayong Yang $1,3, *(\mathbb{D})$ \\ 1 School of Mechanical and Automotive Engineering, Guangxi University of Science and Technology, \\ Liuzhou 545006, China; zhangyanhui@gxust.edu.cn (Y.Z.); 221055097@stdmail.gxust.edu.cn (Y.Z.); \\ 213046610@stdmail.gxust.edu.cn (J.W.); zhangzhiqing@gxust.edu.cn (Z.Z.) \\ 2 Research Center of Guangxi Industry High-Quality Development, Guangxi University of Science and \\ Technology, Liuzhou 545006, China; tandongli@gxust.edu.cn \\ 3 Institute of the New Energy and Energy-Saving \& Emission-Reduction, Guangxi University of Science and \\ Technology, Liuzhou 545006, China \\ * Correspondence: dyyang@gxust.edu.cn
}

Citation: Zhang, Y.; Zhong, Y.; Wang, J.; Tan, D.; Zhang, Z.; Yang, D. Effects of Different Biodiesel-Diesel Blend Fuel on Combustion and Emission Characteristics of a Diesel Engine. Processes 2021, 9, 1984. https:// doi.org/10.3390/pr9111984

Academic Editor: Zhihua Wang

Received: 7 October 2021

Accepted: 4 November 2021

Published: 7 November 2021

Publisher's Note: MDPI stays neutral with regard to jurisdictional claims in published maps and institutional affiliations.

Copyright: (c) 2021 by the authors. Licensee MDPI, Basel, Switzerland. This article is an open access article distributed under the terms and conditions of the Creative Commons Attribution (CC BY) license (https:// creativecommons.org/licenses/by/ $4.0 /)$.

\begin{abstract}
In this paper, biodiesel was used as an alternative fuel to investigate the combustion and emission characteristics of a four-stroke diesel engine, in terms of cylinder pressure, heat release rate, cylinder temperature, brake thermal efficiency, brake specific fuel consumption, nitrogen oxide, soot, carbon monoxide, and hydrocarbon. Firstly, a diesel engine cylinder model was developed by AVL-Fire software coupled with CHEMKIN code to simulate the injection and combustion of biodiesel with a kinetic mechanism with 106 species and 263 reactions. Then, the simulation model was validated by experimental results under $100 \%$ and $50 \%$ load conditions and used to simulate the combustion process of a diesel engine fueled with pure diesel, biodiesel, and biodiesel-diesel blends with 10\%, 20\%,30\% biodiesel by volume, respectively. The results showed that the brake specific fuel consumption increased with the increase of mixed biodiesel ratio. The brake specific fuel consumptions of B10, B20 and B30 increased by 1.1\%, 2.3\% and 3.3\%, respectively, compared with that of D100. The combustion and emission characteristics of the diesel engine are improved. Therefore, biodiesel can be used as an alternative fuel for the diesel engine. The diesel-biodiesel fuel can improve the combustion and emission characteristics of the diesel engine.
\end{abstract}

Keywords: biodiesel; diesel engine; AVL-Fire; biodiesel-diesel blends

\section{Introduction}

Due to the economy and reliability of diesel engines, they have become the primary power source for ships, construction machinery, and heavy trucks [1]. According to the International Energy Agency, the energy consumption rate will reach approximately 53\% in 2030 [2]. As a result, the depletion of fossil fuels will further increase in the short term [3]. However, with the development of society, the energy crisis has become a matter of concern. Thus, the energy crises [4] and environmental problems [5] have driven the development of renewable energy in the world. In addition, the cylinder combustion of diesel engines also emits many pollutants, such as particulate matter, nitrogen oxide, and sulfides. To overcome this problem, almost every country in the world has made stringent emission regulations to reduce pollutant emissions [6].

In order to solve the above problem, many researchers are also looking for clean energy sources such as solar, wind, and biomass to meet future economic development [7]. Because wind energy and solar energy are greatly affected by the natural environment, it is difficult to widely replace petrochemical fuels in a short time [8]. However, the biodiesel produced by animal and vegetable oil in ester exchange reactions, not only has the equivalent petroleum diesel combustion, but also has environmentally-friendly, renewable [9], and other positive features, making it one of the ideal diesel fuels to substitute petroleum [10]. 
Biodiesel is a clean energy source and is considered as the most viable replacement of fossil fuels due to its biodegradable nature [11], low emissions, carbon neutrality, and nontoxicity [12]. Thus, it was defined as an "environmentally friendly fuel" [13]. In general, the specific preparation process is based on a transesterification reaction with animal fats or vegetable oils and with ethanol or methanol as reactants under catalyst conditions, such as potassium hydroxide or sodium hydroxide, where triglycerides are transferred to ethyl esters and fatty acid methyl esters.

Many researchers have carried out experimental and modeling research on the combustion and emission characteristics of diesel engines fueled with various types of biodiesels [14]. It was observed that the use of biodiesel could significantly improve combustion efficiency by releasing oxygen atoms from its chemical structure to replenish oxygen in the fuel-poor zone, thereby reducing particulate matter (PM), carbon monoxide (CO), and hydrocarbon (HC) emissions. Moreover, biodiesel can be miscible with diesel in any ratio. However, biodiesel fuel still has many limitations, such as high viscosity, low calorific value, low volatility, and poor cold flow properties. In addition, biodiesel fuel will increase the nitrogen oxide emission reported by many researchers [15]. Therefore, many researchers have focused on the combustion and emission characteristics of diesel engines fueled with biodiesel-diesel fuel to improve the properties of biodiesel [16].

In order to improve biodiesel characteristic, it is necessary to study the characteristics of biodiesel [17]. For example, Gokalp et al. [18] investigated the effects of diesel-biodiesel fuels with different mixing ratios (5\%,20\% and $50 \%$ biodiesel by volume) on the combustion and performance characteristics of marine diesel engine. The results indicated that the maximum reduction in soot emission reached $74 \%$ compared with that of diesel. However, the brake specific fuel consumption (BSFC) increased due to the lower calorific value of biodiesel. In addition, Karavalakis et al. [19] investigated the effects of diesel-biodiesel fuels on the combustion and performance characteristics of a heavy-duty diesel engine. They found that the diesel-biodiesel fuels could greatly reduce PM, HC, and CO emissions. Mehmet et al. [20] investigated the combustion and emission characteristics of a diesel engine fueled with diesel-biodiesel fuels ( $5 \%$ and $20 \%$ biodiesel by volume). The results showed that the brake thermal efficiency had no obvious change when the engine was fueled with diesel-biodiesel fuel ( $20 \%$ soybean biodiesel by volume) and diesel. Therefore, biodiesel can be considered as an alternative fuel in the diesel engine with changes only in the engine fuel system.

In recent years, with the rapid development of computational fluid dynamics (CFD) technology, numerical simulation has been widely used in engineering design and development [21]. CFD technology can not only save cost, but also better simulate the combustion process in the diesel engine cylinder [22]. For example, Yang et al. [23] used AVL-Fire coupled with the CHEMKIN code to investigate biodiesel-ethanol blended fuel with different proportions of ethanol on the combustion and emission characteristics of the diesel engine at different engine loads. The results showed that the maximum cylinder pressure and indicated thermal efficiency decreased as the ethanol proportion increased. In addition, An et al. [24] investigated the combustion and emission characteristics of a four-stroke, water-cooled, high-pressure common rail turbocharged diesel engine fueled with diesel-biodiesel fuel. The results showed that the fuel blends had a significant effect on BSFC and brake thermal efficiency. Lukas et al. [25] used AVL-Boost coupled with AVL-Fire to investigate the effect of diesel-biodiesel on engine characteristic. The results showed that diesel-biodiesel blends could improve the emission characteristics. Based on previous studies, the results obtained showed that biodiesel fuel could decrease PM, $\mathrm{CO}, \mathrm{HC}$ and $\mathrm{NO}_{\mathrm{x}}$ emissions [26,27], although, on the other hand some experiments on biodiesel also showed that $\mathrm{NO}_{\mathrm{x}}$ emission concentration increased [28,29]. Therefore, it is very important to further study the impact of biodiesel on diesel engine emission and combustion characteristics. It is beneficial to further reducing emissions and improving brake thermal efficiency of the diesel engine. 
As mentioned above, the paper was conducted on the effects of the biodiesel proportion on the combustion and emission characteristics of a biodiesel fueled diesel engine. Firstly, an improved diesel engine model was developed and verified by the experimental results in the AVL-Fire environment. Secondly, the AVL-Fire combined with CHEMKIN code was employed to evaluate the practicality of biodiesel-diesel fuel. Finally, the effects of biodiesel-diesel blend fuels on the combustion and emission characteristics of diesel engine were also investigated and compared. The findings are of interest in terms of both the prevention of performance losses and emission reduction.

\section{Models and Methods}

\subsection{Mathematical Models}

In the paper, mathematical models are used to solve the mass, momentum, energy, and component number conservation equations and describe the combustion of non-constant three-dimensional flow fields for chemical reactions [30-32].

\subsubsection{Cylinder Flow Simulation}

The effects of turbulent fluid flow on fluid should be considered in the AVL-Fire environment. The AVL-Fire solves the momentum, energy, three-dimensional transient conservation equations of mass, turbulent fluid flow and species using the temporaldifferencing scheme and a finite volume. The mass conservation is described as follows:

$$
\frac{\partial \rho}{\partial t}+\frac{\partial(\rho u)}{\partial x}+\frac{\partial(\rho v)}{\partial y}+\frac{\partial(\rho w)}{\partial z}=0
$$

where $\rho$ is the density, $\mathrm{g} / \mathrm{cm}^{3} ; \mathrm{t}$ is the time, $\mathrm{s} ; u=(u, v, w)$ is the vector of the velocity, $\mathrm{m} / \mathrm{s}$;

The momentum of the fluid in the cylinder is divided into three different directions, and the momentum conservations in the $x, y$ and $z$ directions are as follows:

$$
\begin{aligned}
& \rho \frac{d u}{d t}=\frac{\partial\left(-p_{a}+\tau_{x x}\right)}{\partial x}+\frac{\partial \tau_{y z}}{\partial y}+\frac{\partial \tau_{z x}}{\partial z}+S_{M x} \\
& \rho \frac{d v}{d t}=\frac{\partial \tau_{x y}}{\partial x}+\frac{\partial\left(-p_{a}+\tau_{y y}\right)}{\partial y}+\frac{\partial \tau_{z y}}{\partial z}+S_{M y} \\
& \rho \frac{d w}{d t}=\frac{\partial \tau_{x z}}{\partial x}+\frac{\partial \tau_{y z}}{\partial y}+\frac{\partial\left(-p_{a}+\tau_{z z}\right)}{\partial z}+S_{M z}
\end{aligned}
$$

where $p_{a}$ is the normal stress, $\mathrm{Pa} ; \tau$ is viscous stress, $\mathrm{Pa} ; S_{M}$ is the source momentum from each direction.

The energy conservation equation is as follows:

$$
\begin{aligned}
& \frac{\partial(\rho T)}{\partial t}+\frac{\partial(\rho u T)}{\partial x}+\frac{\partial(\rho v T)}{\partial y}+\frac{\partial(\rho w T)}{\partial z} \\
& =\frac{\partial}{\partial x}\left(\frac{k}{c_{p}} \frac{\partial T}{\partial x}\right)-\frac{\partial}{\partial y}\left(\frac{k}{c_{p}} \frac{\partial T}{\partial y}\right)+\frac{\partial}{\partial z}\left(\frac{k}{c_{p}} \frac{\partial T}{\partial z}\right)+S_{T}
\end{aligned}
$$

where $c_{p}$ is specific heat capacity, $\mathrm{J} ; T$ is the temperature, ${ }^{\circ} \mathrm{C} ; k$ is the heat transfer coefficient of fluid; $S_{T}$ is the viscous dissipation, $\mathrm{J}$.

\subsubsection{Combustion Model}

The 3-zones Extended Coherent Flame Model is one of the coherent flame models and has a decoupled treatment of chemistry and turbulence, which makes it an attractive solution for combustion modeling [33]. Thus, it is suitable for the calculation of combustion in the cylinder and can be expressed as:

$$
\frac{\partial \bar{\rho} \widetilde{Y}_{x}}{\partial t}+\frac{\partial \bar{\rho} \widetilde{u}_{i} \widetilde{Y}_{x}}{\partial x_{i}}=\frac{\partial}{\partial x_{i}}\left(\left(\frac{\mu_{L}}{S_{C L}}+\frac{\mu_{T}}{S_{C T}}\right) \frac{\partial \widetilde{Y}_{x}}{\partial x_{i}}\right)+\omega_{x}
$$


where $\mu_{L}$ and $\mu_{T}$ is the laminar and eddy viscosity respectively, $\mathrm{m}^{2} / \mathrm{s} ; S_{C L}$ and $S_{C T}$ is the Schmidt number of laminar and turbulent, $\omega_{x}$ is the corresponding combustion source item, $\mathrm{kg} /\left(\mathrm{m}^{3} \cdot \mathrm{s}\right) ; Y_{x}$ is the average mass fraction of species $\mathrm{x}, \%$.

Furthermore, three transport equations for the mass fraction, mixture fraction, and residual gas mass can be expressed as [34]:

$$
\begin{aligned}
\frac{\partial}{\partial t}\left(\rho y_{f u e l}\right)+\frac{\partial}{\partial x_{i}}\left(\rho u_{i} y_{f u e l}\right) & =\frac{\partial}{\partial x_{i}}\left(\Gamma_{f u} \frac{\partial y_{f u e l}}{\partial x_{i}}\right)+S_{f u} \\
\frac{\partial}{\partial t}(\rho f)+\frac{\partial}{\partial x_{i}}\left(\rho u_{i} f\right) & =\frac{\partial}{\partial x_{i}}\left(\Gamma_{f} \frac{\partial f}{\partial x_{i}}\right) \\
\frac{\partial}{\partial t}(\rho g)+\frac{\partial}{\partial x_{i}}\left(\rho u_{i} f\right) & =\frac{\partial}{\partial x_{i}}\left(\Gamma_{f} \frac{\partial f}{\partial x_{i}}\right)
\end{aligned}
$$

where $y_{f u e l}$ is the fuel mass fraction, $\% ; f$ is the mixture fraction, $\% ; g$ is the residual gas mass, $\mathrm{g}$; $S_{f u}$ is the source term quantifying the fuel evaporation in fresh gases, $\mathrm{kg} / \mathrm{m}^{3} \cdot \mathrm{s}$; and $\rho$ is the mean density of the mixture, $\mathrm{g} / \mathrm{cm}^{3}$.

In addition, the fuel mass fraction in the fresh gases was calculated from the transport equation:

$$
\frac{\partial \bar{\rho} y_{f u . f}}{\partial t}+\frac{\partial \bar{\rho} u_{i} y_{f u . f}}{\partial x_{i}}=\frac{\partial}{\partial x_{i}}\left[\left(\frac{\mu_{L}}{S_{C L}}+\frac{\mu_{L}}{S_{C T}}\right) \frac{\partial y_{f u . f}}{\partial x_{i}}\right]+\bar{\rho} S_{f u . f}+\omega_{f u . f}
$$

where $y_{f u . f}$ is the fuel mass fraction in the fresh gases, $\% ; \omega_{f u . f}$ is a source term taking auto-ignition, premixed flame and mixing between mixed unburned and mixed burnt areas into account, $\mathrm{kg} /\left(\mathrm{m}^{3} \cdot \mathrm{s}\right)$.

Additionally, the mixing of evaporated fuel with fresh air is modeled with the transport equations for the unmixed fuel and unmixed oxygen [35,36]. It can be calculated by:

$$
\begin{aligned}
\frac{\partial \bar{\rho} y_{f}}{\partial t}+\frac{\partial \bar{\rho} u_{i} y_{f}}{\partial x_{i}} & -\frac{\partial}{\partial x_{i}}\left(\frac{\mu_{L}}{S_{C L}} \frac{\partial \bar{\rho} y_{f}}{\partial x_{i}}\right) \frac{\partial y_{f}}{\partial x_{i}}=\bar{\rho} S_{f}-\frac{1}{\tau_{m}} y_{f}\left(1-y_{f} \frac{\bar{\rho} M_{m i x}}{\bar{\rho}_{u} M_{f}}\right) \\
& \frac{\partial \bar{\rho} y_{a . o_{2}}}{\partial t}+\frac{\partial \bar{\rho} u_{i} y_{a . o_{2}}}{\partial x_{i}}-\frac{\partial}{\partial x_{i}}\left(\frac{\mu_{L}}{S_{C L}} \frac{\partial \bar{\rho} y_{a . o_{2}}}{\partial x_{i}}\right) \frac{\partial y_{a . o_{2}}}{\partial x_{i}} \\
& =\bar{\rho} S_{f}-\frac{1}{\tau_{m}} y_{a . o_{2}}\left(1-\frac{y_{a . o_{2}}}{y_{\infty . o_{2}}} \frac{\bar{\rho} M_{m i x}}{\bar{\rho}_{u} M_{f}}\right)
\end{aligned}
$$

where $y_{f}$ is the unmixed fuel, $\mathrm{g} ; y_{a .02}$ is the unmixed oxygen, $\mathrm{cm}^{3} ; M_{\text {mix }}$ is the mean molar mass of the gases in the mixed area, $\mathrm{g} ; M_{f}$ is the molar mass of fuel, $\mathrm{g} ; \rho_{u}$ is the density of the unburnt fuel, $\mathrm{g} / \mathrm{cm}^{3} ; \tau_{m}$ is the mixing time which considers turbulence quantities, $\mathrm{s}$; and is defined as:

$$
\frac{1}{\tau_{m}}=\beta \frac{\varepsilon}{k}
$$

where $\beta$ is a model factor $(\beta=1) ; \varepsilon$ is the dissipation rate, $\% ; k$ is the isentropic exponent, pa.

\subsubsection{Breakup Model}

In the paper, the Kelvin-Helmholtz wave model [37] is employed to simulate the breakup of fuel droplets and can be expressed as:

$$
\begin{gathered}
R_{a}=C_{1} \lambda \\
\tau_{a}=\frac{3.7 C_{2} R_{a}}{\lambda V} \\
\lambda=f\left(W_{e c}, O h_{d}\right) \\
V=f\left(W_{e c}, O h_{d}\right)
\end{gathered}
$$


where $R_{a}$ is the radius of a new oil drop, $\mathrm{mm} ; \lambda$ is the length of wave, $\mathrm{mm} ; V$ is the wave growth rate, $\mathrm{mm} / \mathrm{s} ; \tau_{a}$ is the breaking time, $\mathrm{s} ; C_{1}$ is the model constant; $C_{2}$ is the braking rime constant; $W_{e c}$ is indicating continuous phase; $O_{h d}$ is indicating droplet properties.

In order to estimate the disintegration of the blobs into secondary droplets, RTinstabilities can develop if the fluid acceleration has an opposite direction to the density gradient [38]. RT-instabilities can be calculated by the following equations:

$$
\begin{gathered}
\Omega_{t}=\sqrt{\frac{2}{3 \sqrt{3 \sigma}} \frac{g_{t}\left|\left(\rho_{d}-\rho_{c}\right)\right|^{1.5}}{\rho_{d}+\rho_{c}}} \\
\tau_{t}=C_{5} \frac{1}{\Omega_{t}} \\
K_{t}=\sqrt{\frac{g_{t}\left|\rho_{d}-\rho_{c}\right|}{3 \sigma}} \\
\lambda_{t}=C_{4} \frac{\pi}{K_{t}}
\end{gathered}
$$

where $g_{t}$ is the deceleration in the direction of travel, $\mathrm{m} / \mathrm{s}^{2}$; if the wave length $\lambda$ is small enough to be growing on the droplet's surface and the characteristic RT breakup time $\tau_{t}$ has passed, the droplets atomize and their new sizes are assumed to be proportional to RT wavelength; $\sigma$ is the surface tension coefficient; $K_{t}$ is the number of waves; $\rho_{d}$ is the density of liquid phase, $\mathrm{g} / \mathrm{cm}^{3} ; \rho_{c}$ is the density of gas phase, $\mathrm{g} / \mathrm{cm}^{3} ; C_{4}$ and $C_{5}$ are the adjust parameters.

\subsubsection{Turbulence Model}

The standard $k-\varepsilon$ model can be calculated by the following equations:

$$
\begin{gathered}
\frac{\partial(\rho k)}{\partial t}+\operatorname{div}(\rho k U)=\operatorname{div}\left[\frac{\mu_{t}}{\sigma_{k}} g r a d k\right]+2 \mu_{t} S_{i j} \cdot S_{i j}-\rho \varepsilon \\
\frac{\partial(\rho \varepsilon)}{\partial t}+\operatorname{div}(\rho \varepsilon U)=\operatorname{div}\left[\frac{\mu_{t}}{\sigma_{\varepsilon}} \operatorname{grad\varepsilon }\right]+C_{1 \varepsilon} \frac{\varepsilon}{k} 2 \mu_{t} S_{i j} \cdot S_{i j}-C_{2 \varepsilon} \rho \frac{\varepsilon^{2}}{k}
\end{gathered}
$$

where $C_{\mu}, \sigma_{k}, \sigma_{\varepsilon}, C_{1 \varepsilon}$, and $C_{2 \varepsilon}$.are the adjustable constants. In this paper, $C_{\mu}, \sigma_{k}, \sigma_{\varepsilon}, C_{1 \varepsilon}$, and $C_{2 \varepsilon}$ are $0.09,1.00,1.30,1.44$ and 1.92 , respectively.

\subsubsection{Heat Transfer Model}

Heat transfer in the cylinder is a very complex process [39,40]. The important factor in the calculation of heat transfer is to determine the instantaneous average heat transfer coefficient, which can reduce the error. In this paper, the instantaneous average heat transfer coefficient was calculated by the following equation:

$$
\alpha_{e}=820 p^{0.8} \cdot T^{-0.53} \cdot d^{-0.2}\left[C_{a} \cdot C_{v}+C_{b} \frac{T_{1} \cdot V_{s}}{p_{1} V_{1}}\left(p-p_{0}\right)\right]^{0.8}
$$

where $p$ is the cylinder pressure, $\mathrm{MPa} ; T$ is the cylinder temperature, $\mathrm{K} ; C_{a}$ is the air velocity coefficient; $C_{v}$ is the velocity of the cylinder, $\mathrm{m} / \mathrm{s} ; C_{b}$ is the chamber shape coefficient; $P_{1}$, $T_{1}$ and $V_{1}$ is the cylinder pressure, temperature and volume when the piston move to the beginning of the compression stroke, respectively, $V_{s}$ is the cylinder work capacity, $\mathrm{m}^{3} ; p_{0}$ is the cylinder pressure measured by dynamic test branch, $\mathrm{MPa}$.

\subsection{Fuel Preparation}

According to our team's previous research [12,41], the typical biodiesels are mainly composed by five components, methyl palmitate $\left(\mathrm{C}_{17} \mathrm{H}_{34} \mathrm{O}_{2}, \mathrm{C} 16: 0\right)$ and methyl stearate $\left(\mathrm{C}_{19} \mathrm{H}_{38} \mathrm{O}_{2}, \mathrm{C} 18: 0\right)$ as saturated methyl esters, as well as methyl oleate $\left(\mathrm{C}_{19} \mathrm{H}_{36} \mathrm{O}_{2}, \mathrm{C} 18: 1\right)$, 
methyl linoleate $\left(\mathrm{C}_{19} \mathrm{H}_{34} \mathrm{O}_{2}, \mathrm{C} 18: 2\right)$ and methyl linolenate $\left(\mathrm{C}_{19} \mathrm{H}_{32} \mathrm{O}_{2}, \mathrm{C} 18: 3\right)$ as unsaturated methyl esters. Where $\mathrm{Cm}: \mathrm{n}$ is the shorthand of fatty acid methyl ester, $\mathrm{m}$ is the number of carbon atoms in fatty acid group, $\mathrm{n}$ is the number of double bonds. It is generally believed that the major components of typical biodiesels are also the above five components, and other components such as C12:0, C14:0 and C20:0 can be ignored. The soybean oil methyl ester (SME) was obtained by transesterification of soybean oil with methanol. The transesterification of soybean oil was conduct out by alkali catalysis in a reactor about $1 \mathrm{~h}$. The transesterification was carried out with 6:1 methanol to oil molar ratio and $1 \% \mathrm{wt} \mathrm{KOH}$ as an alkaline catalyst. Based on the fatty acid profile, the SME properties were analyzed by "Biodiesel Analyzer". In the paper, an Agilent 7890 N GC-MS analyzer was used for measuring the composition of fatty acid of biodiesel. Table 1 shows the fatty acid profile of biodiesel. In addition, the kinematic viscosity of biodiesel is measured according to ASTM D445. Similarly, the lower calorific value of biodiesel is measured according to ASTM D240.

Table 1. Physical properties of FAME present [12].

\begin{tabular}{|c|c|c|c|c|c|}
\hline Type & $\begin{array}{l}\text { Kinetic Viscosity } \\
\left(\mathrm{mm}^{2} / \mathrm{s}\right)\left(\text { at } 40^{\circ} \mathrm{C}\right)\end{array}$ & $\begin{array}{c}\text { Density } \\
\left(\mathrm{g} / \mathrm{cm}^{3}\right)\left(\text { at } 20{ }^{\circ} \mathrm{C}\right)\end{array}$ & $\begin{array}{l}\text { Molecular Weight } \\
\text { (g/mol) }\end{array}$ & $\begin{array}{c}\text { Higher Calorific Value } \\
(\mathrm{MJ} / \mathrm{kg})\end{array}$ & $\begin{array}{c}\text { SME } \\
(\%)\end{array}$ \\
\hline C18:3 & 3.11 & 0.899 & 292 & 39.43 & 6.19 \\
\hline C18:2 & 3.79 & 0.887 & 294 & 39.68 & 55.19 \\
\hline C18:1 & 4.60 & 0.875 & 296 & 39.93 & 23.43 \\
\hline C18:0 & 5.59 & 0.863 & 298 & 40.18 & 3.22 \\
\hline C16:0 & 4.37 & 0.864 & 270 & 39.56 & 11.98 \\
\hline
\end{tabular}

In addition, Table 2 gives some physical and chemical properties of diesel and soybean biodiesel. In order to investigate the effect of different proportions of biodiesel on engine combustion and performance, three different biodiesel-diesel fuels (10\%, 20\%, and 30\%, biodiesel by volume) were investigated, where $10 \%$ biodiesel addition mixtures with $90 \%$ diesel by volume, $20 \%$ biodiesel addition mixtures with $80 \%$ diesel by volume, $30 \%$ biodiesel addition mixtures with 70\% diesel by volume, and pure biodiesel (B100), pure diesel (D100), were defined as B10, B20, and B30, respectively.

Table 2. Properties of different injection fuels.

\begin{tabular}{cccccc}
\hline Name & Diesel & SME & B10 & B20 & B30 \\
\hline Cetane number & 50 & 53.65 & 50.37 & 50.73 & 51.10 \\
Lower calorific value $(\mathrm{MJ} / \mathrm{kg})$ & 42.7 & 39.72 & 42.40 & 42.10 & 41.81 \\
Density at $15^{\circ} \mathrm{C}$ & 837 & 886 & 841.9 & 846.8 & 851.7 \\
Oxygen content $(\%)$ & 0.3 & 10.5 & 1.32 & 2.34 & 3.36 \\
Viscosity $\left(\mathrm{cPs} / 40^{\circ} \mathrm{C}\right)$ & 2.75 & 4.31 & 2.91 & 3.06 & 3.22 \\
\hline
\end{tabular}

\subsection{Computational Mesh}

To investigate the effect of biodiesel-diesel on the combustion and emission characteristics of the diesel engine, a turbocharged, compression-ignition, air-cooled, four-stroke diesel engine cylinder model was established in the AVL-Fire environment. The main parameters of the diesel engine are set out in Table 3. Based on the bowl geometry of a diesel engine by taking advantage of the symmetric distribution of eight nozzle holes, the grid is produced. As shown in Figure 1, the $45^{\circ}$ sector dynamic meshes have been considered for one injector nozzle hole. 
Table 3. Engine specifications.

\begin{tabular}{cc}
\hline Type & Value \\
\hline Number of cylinder & 4 \\
Bore $\times$ stroke $(\mathrm{mm})$ & $93 \times 102$ \\
Engine speed $(\mathrm{rpm})$ & 1800 \\
Effective power $(\mathrm{kW})$ & 75 \\
Torque $(\mathrm{N} \cdot \mathrm{m})$ & 240 \\
Connecting rod $(\mathrm{mm})$ & 158.5 \\
Compression ratio & 18 \\
\hline
\end{tabular}

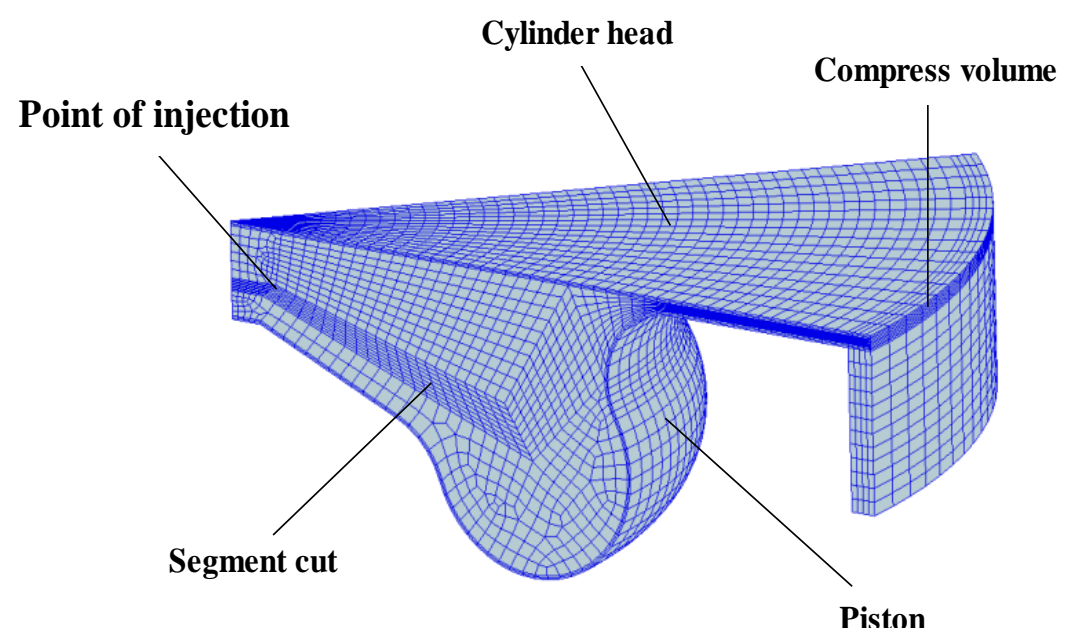

Figure 1. The detailed simulation model of the cylinder.

In this work, the grid-independence validation was verified by using AVL-Fire. Three different kinds of grids were divided, named as coarse mesh, medium mesh, and fine mesh When the piston is at the top dead center, the numbers of the three grids are shown in Figure $2 \mathrm{a}-\mathrm{c}$, and the gird units are $76,072,312,864$, and 654,376 , respectively.

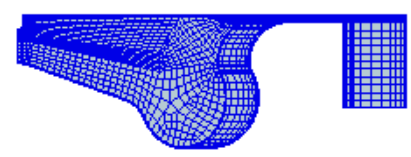

(a) Coarse mesh

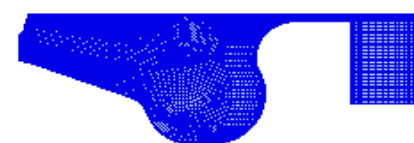

(b) Medium mesh

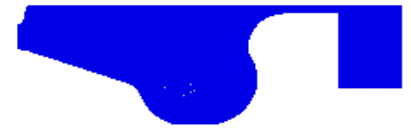

(c) Fine mesh

Figure 2. The cylinder gird at top dead center. (a) Coarse mesh; (b) Medium mesh; (c) Fine mesh.

Figure $3 \mathrm{a}, \mathrm{b}$ shows the cylinder pressure and in-cylinder temperature data at different grid densities. It can be found that there is no clear difference in cylinder pressure and temperature between the fine mesh and medium mesh. This means the calculation result is not affected by the mesh. Since the medium grid can ensure accuracy and save calculation time, the medium grid is selected for the research in this paper. 


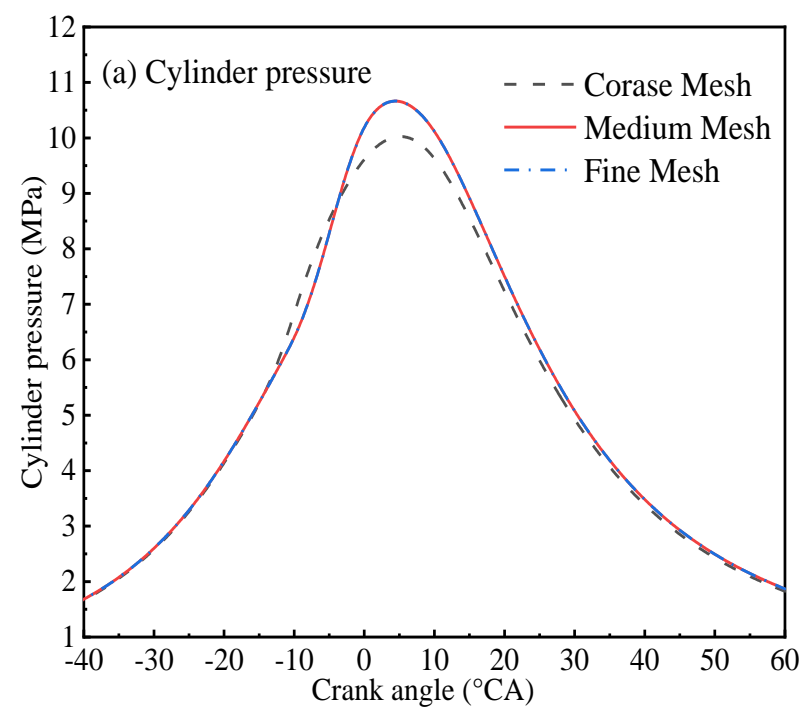

(a)

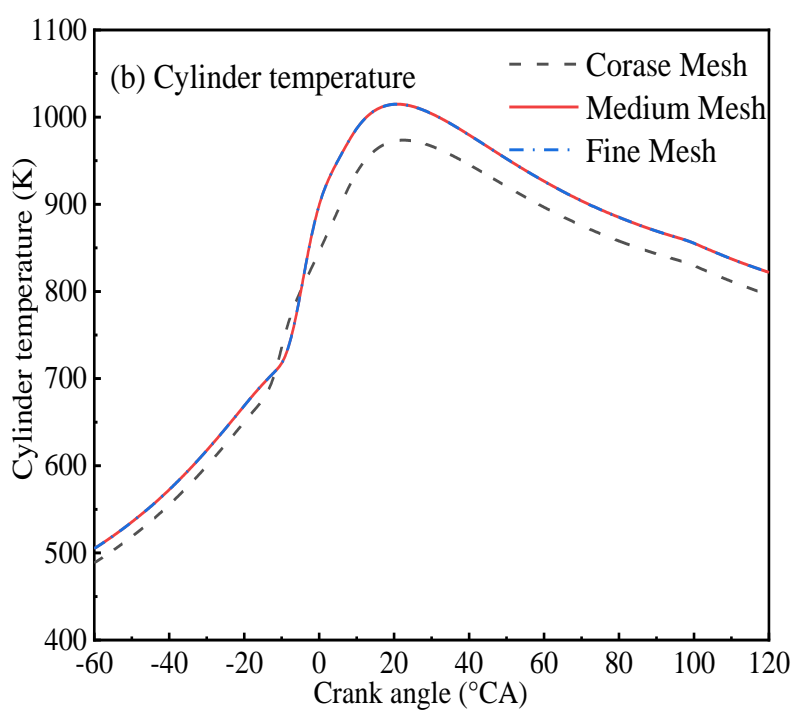

(b)

Figure 3. The comparison of cylinder pressure and temperature for grid independence test. (a) Cylinder temperature (b) Cylinder temperature.

\subsection{Feasibility Test}

In this paper, the diesel engine model was employed to investigate the effects of different diesel-biodiesel fuels on engine performance and emission characteristics of the diesel engine. Figure 4 shows the schematic diagram of diesel engine test equipment.

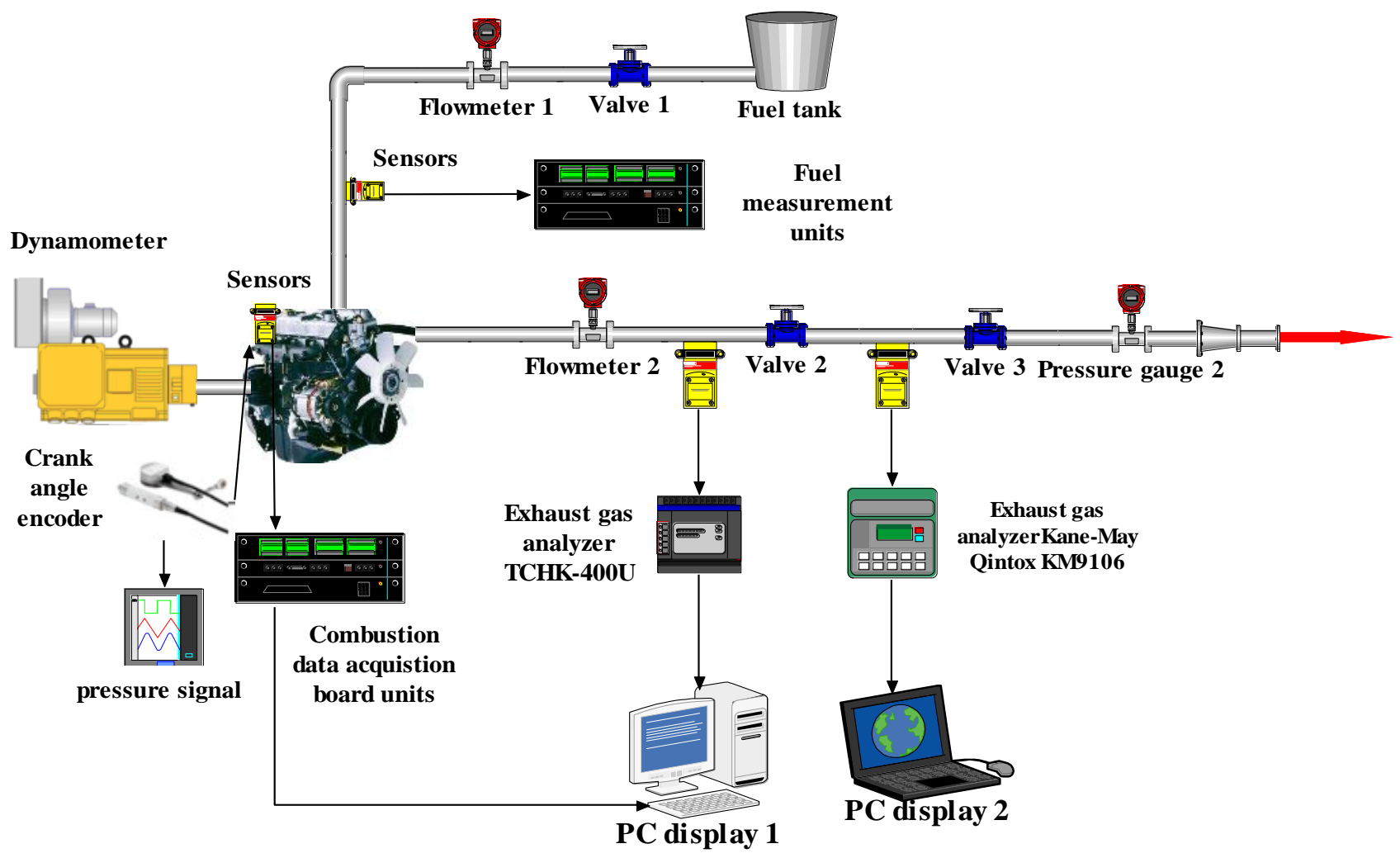

Figure 4. Schematics of experimental device.

The intake and exhaust gases with the engine temperature were measured by the exhaust gas analyzer TCHK-400U. The BILSA MOD210 infrared gas analyzer measured the 
emissions of carbon monoxide, carbon dioxide, and hydrocarbons. The electrochemical gas analyzer Kane-May Qintox KM9106 measured the nitrogen oxides using the AVL-Smoke meter measuring the smoke. The FCMM-2 was used to measure BSFC. The DEWE-2010CA was used to monitor the combustion of the diesel engine. The EFS-IFR600 was used to measure fuel injection rate with a measurement error of $0.5 \%$. A hydraulic dynamometer was used to measure diesel engine load. In addition, an Electronic Control Unit control system was employed for controlling the electronically-controlled diesel engine.

\subsection{Uncertainty Analysis}

In general, the experimental measurements obtained have some uncertainties and errors. The uncertainty in the experimental results is due to many reasons such as sensor selection, observation and calibration. The measurements are used to calculate the desired experimental results. The percentage of uncertainty of various parameters such as $\mathrm{NO}_{\mathrm{x}}$ BSFC and BTE can be obtained by the following equations:

$$
\begin{gathered}
E_{R}=\left\{\left[\left(\partial R / \partial Y_{1}\right) e_{1}\right]^{2}+\left[\left(\partial R / \partial Y_{2}\right) e_{2}\right]^{2}+\cdots+\left[\left(\partial R / \partial_{n}\right) e_{n}\right]^{2}\right\}^{1 / 2} \\
R=\left\{Y_{1}, Y_{2}, Y_{3}, \cdots, Y_{n}\right\}
\end{gathered}
$$

where $R$ in Equation (26) is a function of independent variable $Y_{1}, Y_{2}, \ldots, Y_{n}$. Let $e_{1}, e_{2}$, $\ldots$, and $e_{n}$ be the uncertainties in the independent variables and $E_{R}$ be the uncertainty in the results.

The measuring range and accuracy of the measurement equipment used in this paper are shown in Table 4. The overall experimental uncertainly has been calculated by the following equation.

Overall experimental uncertainty $=$ Square root of [(uncertainty of

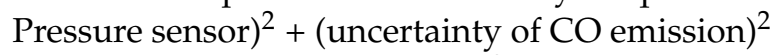

+ (uncertainty of $\mathrm{CO}_{2}$ emission $)^{2}$

+ (uncertainty of $\mathrm{HC}$ emission $)^{2}$

$+{\text { (uncertainty of Soot emission })^{2}}^{2}$

$+\left(\text { uncertainty of } \mathrm{NO}_{x} \text { emission }\right)^{2}$

+ (uncertainty of BSFC) $)^{2}$

$+{\left.\text { (uncertainty of Crank angle encoder })^{2}\right]}^{2}$

$=$ Square root of $\left[(0.5)^{2}+(1)^{2}+(1)^{2}+(1)^{2}+(0.5)^{2}+(1)^{2}+(1.5)^{2}+(0.3)^{2}\right]=2.615 \%$

Table 4. List of measurements, measuring accuracy, and measuring range.

\begin{tabular}{cccc}
\hline Measurements & Measuring Range & Accuracy & \% Uncertainty \\
\hline Pressure sensor & $0-25 \mathrm{MPa}$ & $\pm 10 \mathrm{kPa}$ & \pm 0.5 \\
Exhaust gas temperature & $0-1000{ }^{\circ} \mathrm{C}$ & $\pm 1{ }^{\circ} \mathrm{C}$ & \pm 0.25 \\
Engine speed & $1-4000 \mathrm{rpm}$ & $\pm 0.2 \%$ & \pm 0.24 \\
Fuel flow measurement & $0.5-100 \mathrm{~L} / \mathrm{h}$ & $\pm 0.04 \mathrm{~L} / \mathrm{h}$ & \pm 0.5 \\
$\mathrm{CO}$ emission & $0-16 \% \mathrm{vol}$ & $\pm 0.01 \%$ & \pm 1 \\
$\mathrm{CO}_{2}$ emission & $0-16 \% \mathrm{vol}$ & $\pm 0.01 \%$ & \pm 1 \\
$\mathrm{HC}$ emission & $0-20000 \mathrm{ppm}$ & $\pm 0.5 \%$ & \pm 1 \\
Soot emission & $0-5000 \mathrm{ppm}$ & $\pm 0.1 \%$ & \pm 0.5 \\
NOx emission & $0-6000 \mathrm{ppm}$ & $\pm 0.1 \%$ & \pm 1 \\
BSFC & - & $\pm 5 \mathrm{~g} / \mathrm{kW}-\mathrm{h}$ & \pm 1.5 \\
Crank angle encoder & $0-720^{\circ} \mathrm{CA}$ & $\pm 0.125^{\circ}$ & \pm 0.3 \\
\hline
\end{tabular}

\subsection{Model Validation}

In order to validate the model, the engine experiments were carried out with a fourcylinder diesel engine fueled with D100 and B10 at different loads. The heat release rate (HRR) and in-cylinder pressure of pure diesel and B10 were shown in Figure 5a-d at 100\% and $50 \%$ loads. The predicted in-cylinder pressure and ignition process were satisfactory 
with the experimental data at $100 \%$ and $50 \%$ loads. The predicted in-cylinder pressure and ignition process agrees well with the experimental results. The difference between experiments and simulations can be explained by the chemical reactions and the sub-grid being considered as a perfect stirred reactor in the CHEMKIN code environment. In addition, Figure $6 \mathrm{a}, \mathrm{b}$ showed the $\mathrm{NO}_{\mathrm{x}}$ emissions of the simulation and experiment at $100 \%$, $50 \%$ and $25 \%$ loads, respectively. It can be found that the skeletal chemical mechanism (SCM) agrees well with the experiment. In general, the SCM and computational modeling can accurately predict the combustion process of biodiesel-diesel fuel.
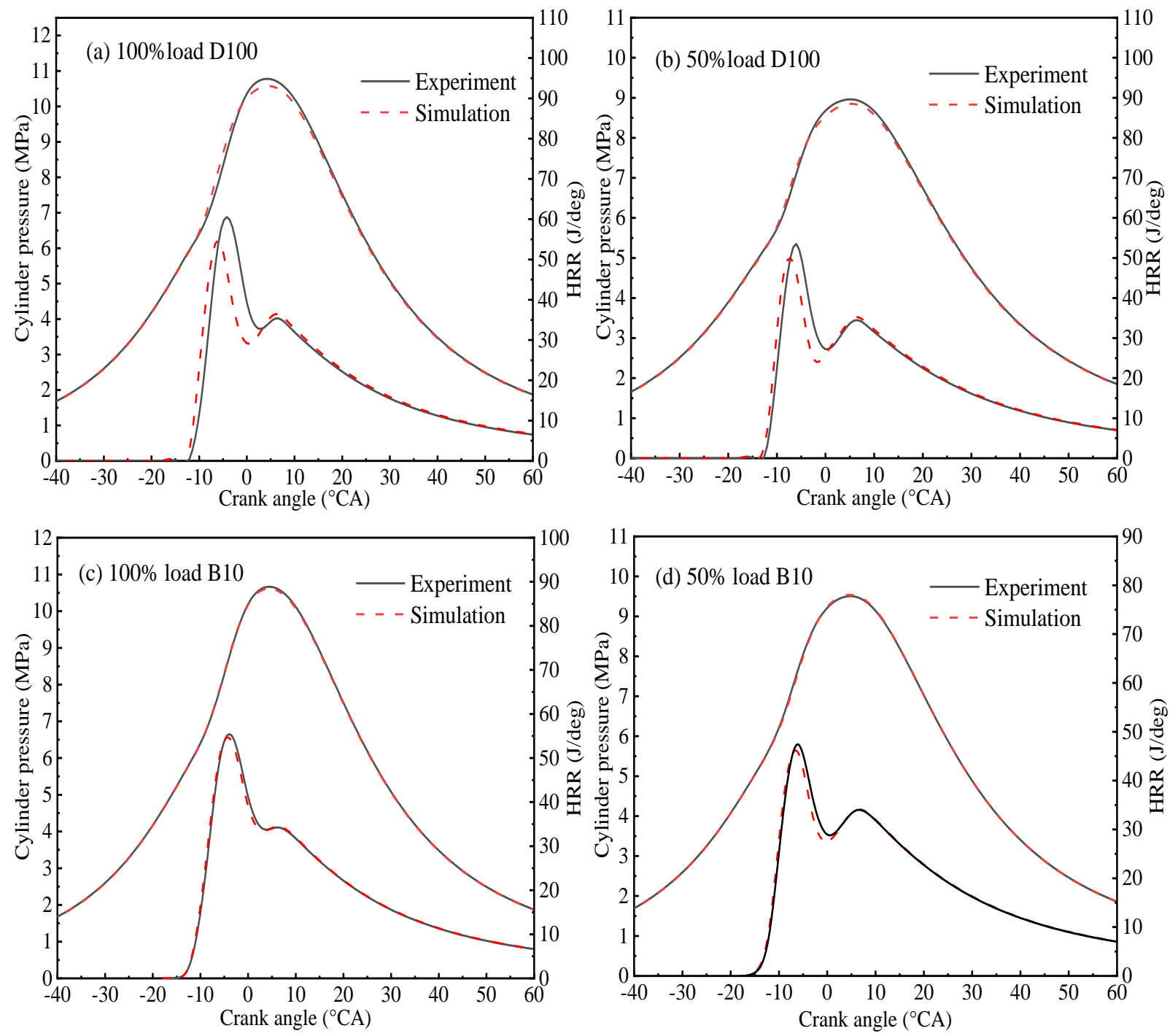

Figure 5. Engine validation results for cylinder pressure and HRR curve: (a) Pure diesel at 100\% load; (b) pure diesel at 50\% load: (c) B10 at 100\% load; (d) B10 at 50\% load. 


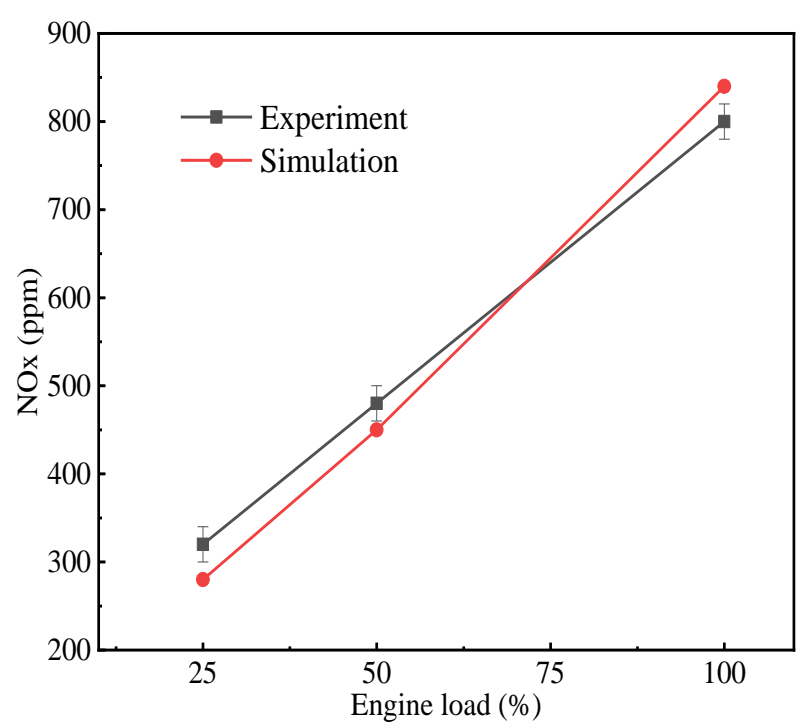

(a)

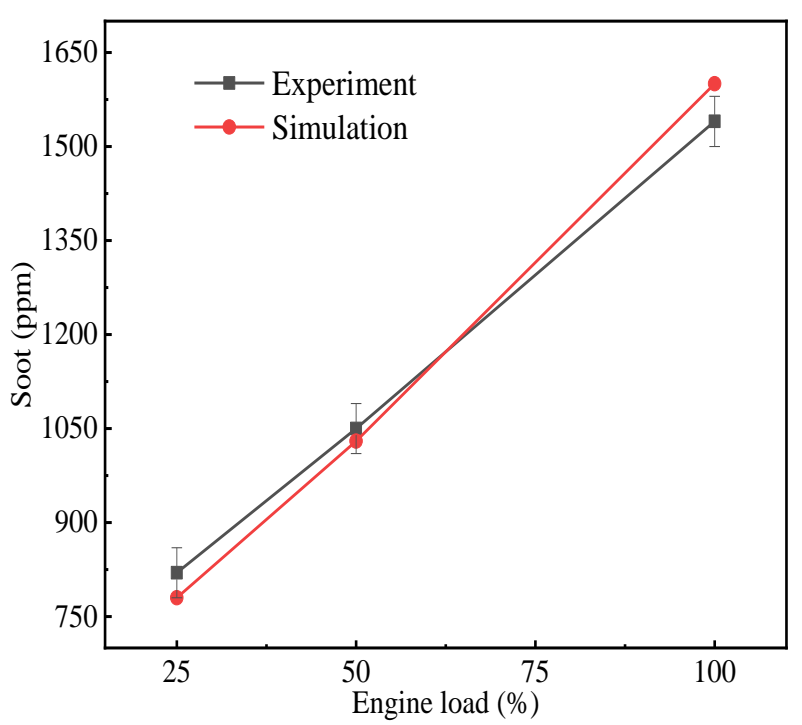

(b)

Figure 6. Engine validation results for emissions: (a) NOx validation; (b) Soot validation.

\section{Results and Discussion}

In this section, the combustion and emission characteristics of the diesel engine fueled with biodiesel and biodiesel-diesel fuels are investigated at different engine loads.

\subsection{Combustion Characteristics}

\subsubsection{Cylinder Pressure and Heat Release Rate}

Cylinder pressure is an important parameter for evaluating the engine combustion process and combustion efficiency [42]. Figure 7a-c shows cylinder pressures and heat release rates of diesel-biodiesels with different biodiesel mixing ratios at different loads. It can be seen that the cylinder pressure of D100 is the highest. More specifically, the cylinder pressures of B100, B30, B20 and B10 are decreased by $4.69 \%, 3.62 \%, 3.52 \%$, and $3.25 \%$, respectively, compared with that of D100 at low load. In addition, the cylinder pressures of B100, B30, B20 and B10 are decreased by $4.22 \%, 3.37 \%, 3.25 \%$ and $3.12 \%$, respectively at full load compared with that of D100. This result is due to the lower calorific value and higher viscosity of biodiesel [43]. When the engine load increases, the spray character is improved by the increase of cylinder temperature. Thus, the difference in cylinder pressure is reduced.

Generally, the ignition delay includes chemical ignition delay and physical ignition delay. The physical ignition delay has the greater impact on ignition character. The D100 shows the earliest ignition delay in all cases, followed by B10, B20 and B10. The ignition delay will increase with the higher viscosity of biodiesel. However, the longer ignition delay is beneficial to the physical evaporation and mixing process of air and fuel. In addition, the pressure, temperature and fuel-air ratio are increased significantly, which are favorable for fuel evaporation and combustion with the increase of engine load, although the ignition delay is still longer for biodiesel. More combustible mixture is prepared during the ignition time. Thus, B100 has the highest HRR. 

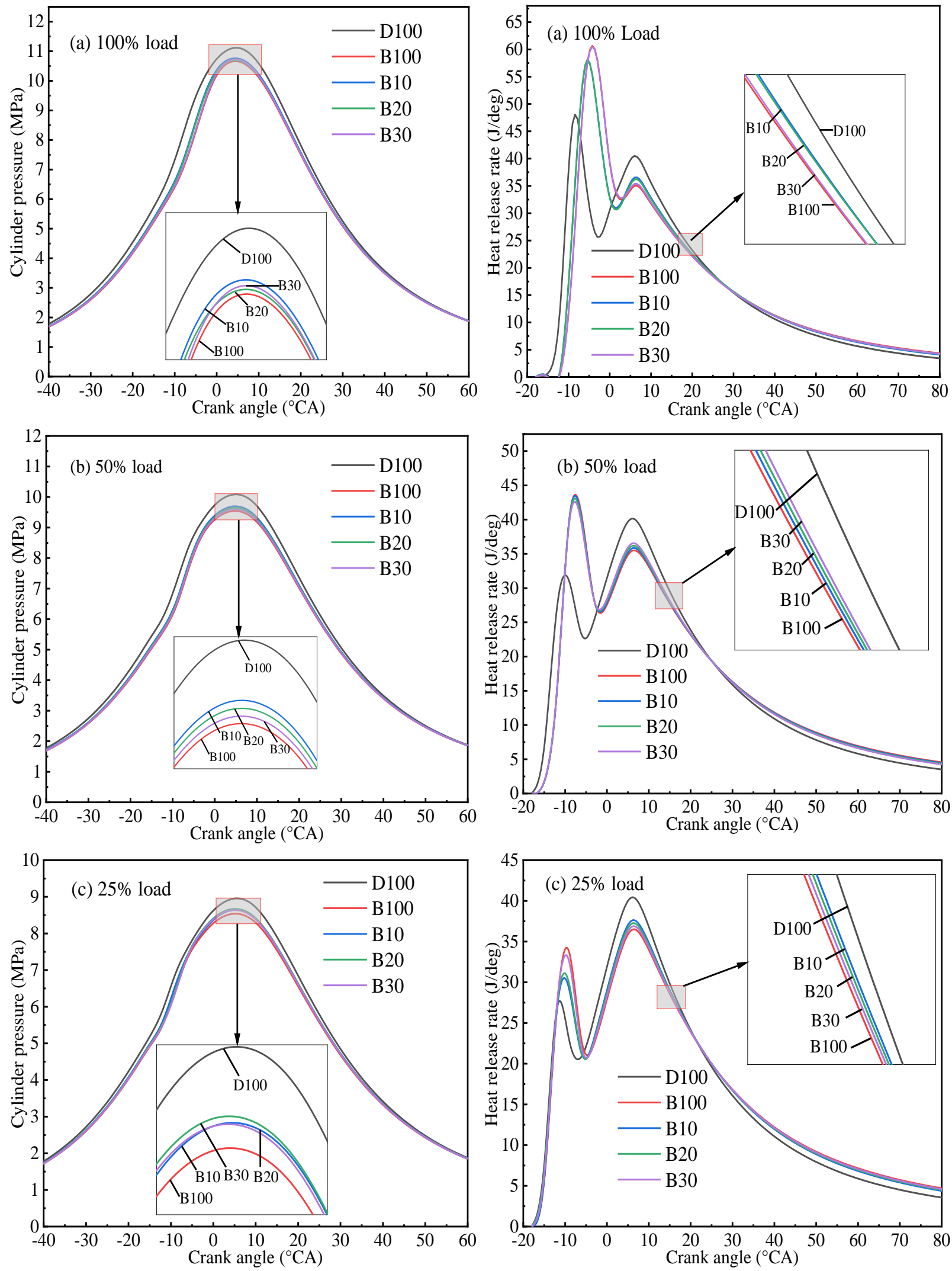

Figure 7. Cylinder pressure and heat release rate at different loads: (a) Cylinder pressure at 100\% load and heat release rate at $100 \%$ load; (b) Cylinder pressure at 50\% load and heat release rate at 50\% load; (c) Cylinder pressure at $25 \%$ load and heat release rate at $25 \%$ load. 


\subsubsection{Cylinder Temperature}

Cylinder temperature is an important parameter for evaluating the combustion and emission characteristics [44]. Figure 8a-c shows cylinder temperatures of diesel-biodiesels with different biodiesel mixing ratios at different loads. It can be found that the maximum cylinder temperature increases with the increases in engine load and the biodiesel mixing ratio. For example, the cylinder temperatures of D100, B10, B20 and B30 are $1312.05 \mathrm{~K}$, $1230.65 \mathrm{~K}, 1220.23 \mathrm{~K}, 1210.03 \mathrm{~K}$ and $1200.31 \mathrm{~K}$, respectively, at full load. This result is due to the low calorific value of biodiesel. In addition, it can be found that cylinder temperature difference between diesel and diesel-biodiesel fuels is reduced with increase in the engine load. This is due to the fact that the oxygen content in biodiesel is beneficial to the combustion, especially at high load. This indicates that the biodiesel mixing ratio has a great effect on the HRR in the cylinder [45].
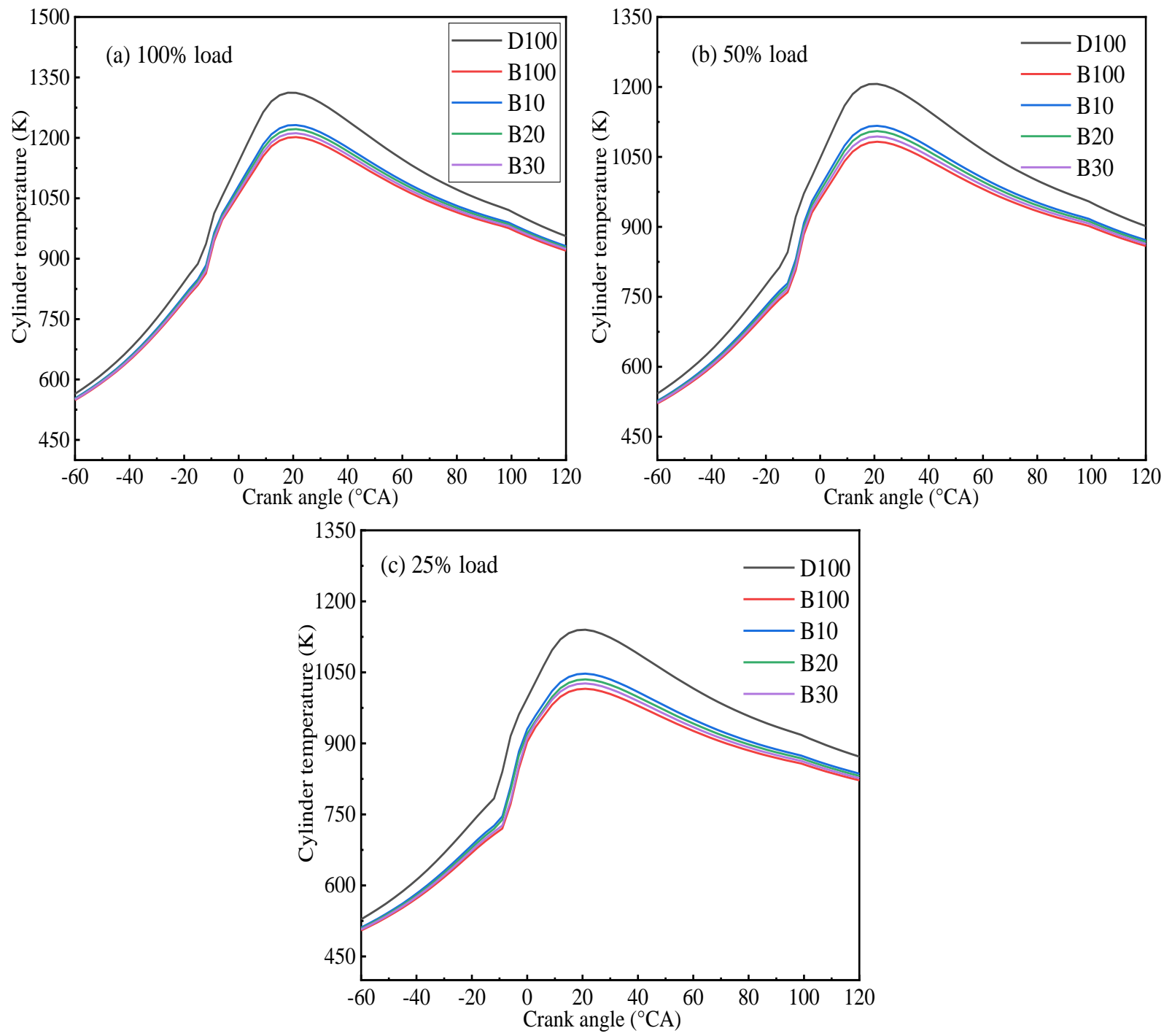

Figure 8. The effects of biodiesel rates on cylinder temperature at different loads: (a) Cylinder temperature at $100 \%$ load; (b) Cylinder temperature at 50\% load; (c) Cylinder temperature at $25 \%$ load.

Figure 9 shows the in-cylinder temperature distribution fields at different loads. It can be seen that more local high-temperature zone is produced by biodiesel compare with diesel, especially at low load. This result is due to the fact that the high viscosity of biodiesel is not beneficial to the fuel spray. Moreover, it was observed that the spray penetration of biodiesel decreased due to the high viscosity of biodiesel, but the spray 
angle increased. Thus, more local high-temperature areas will be produced by the biodiesel. In addition, it was observed that with the increase of biodiesel mixing ratio, the spray impingement improved. Therefore, due to the poor spray penetration of biodiesel [46], the local high-temperature zone will increase at low load, leading to the formation of nitrogen oxides.

D100

B100

B10

B20

$\mathrm{B} 30$
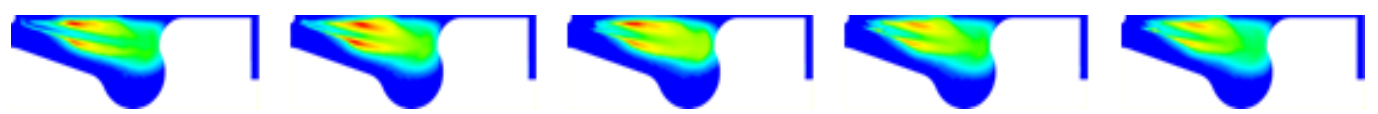

$\mathrm{TDC}=0^{\circ} \mathrm{CA}$
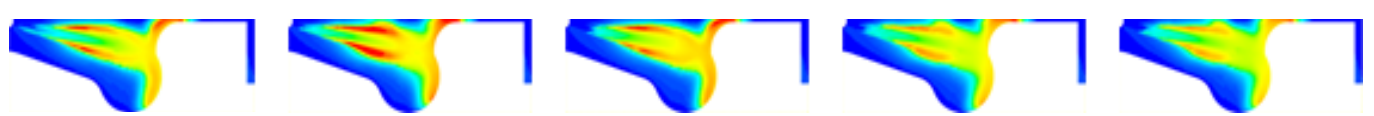

$\mathrm{TDC}=2{ }^{\circ} \mathrm{CA}$

$100 \%$
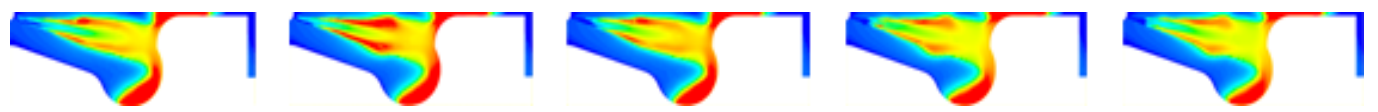

load

$\mathrm{TDC}=4^{\circ} \mathrm{CA}$
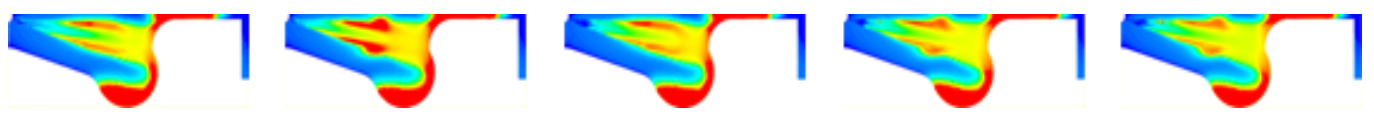

$\mathrm{TDC}=6^{\circ} \mathrm{CA}$
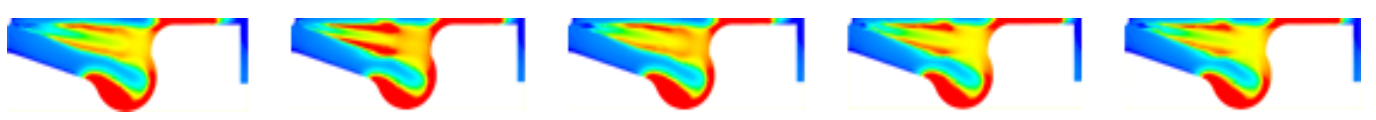

$\mathrm{TDC}=8^{\circ} \mathrm{CA}$

Flow:Temperature[K]

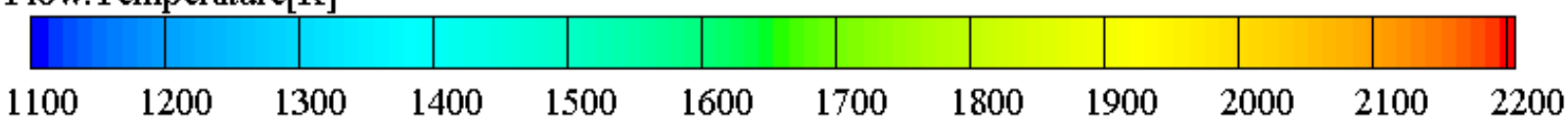

Figure 9. Cont. 


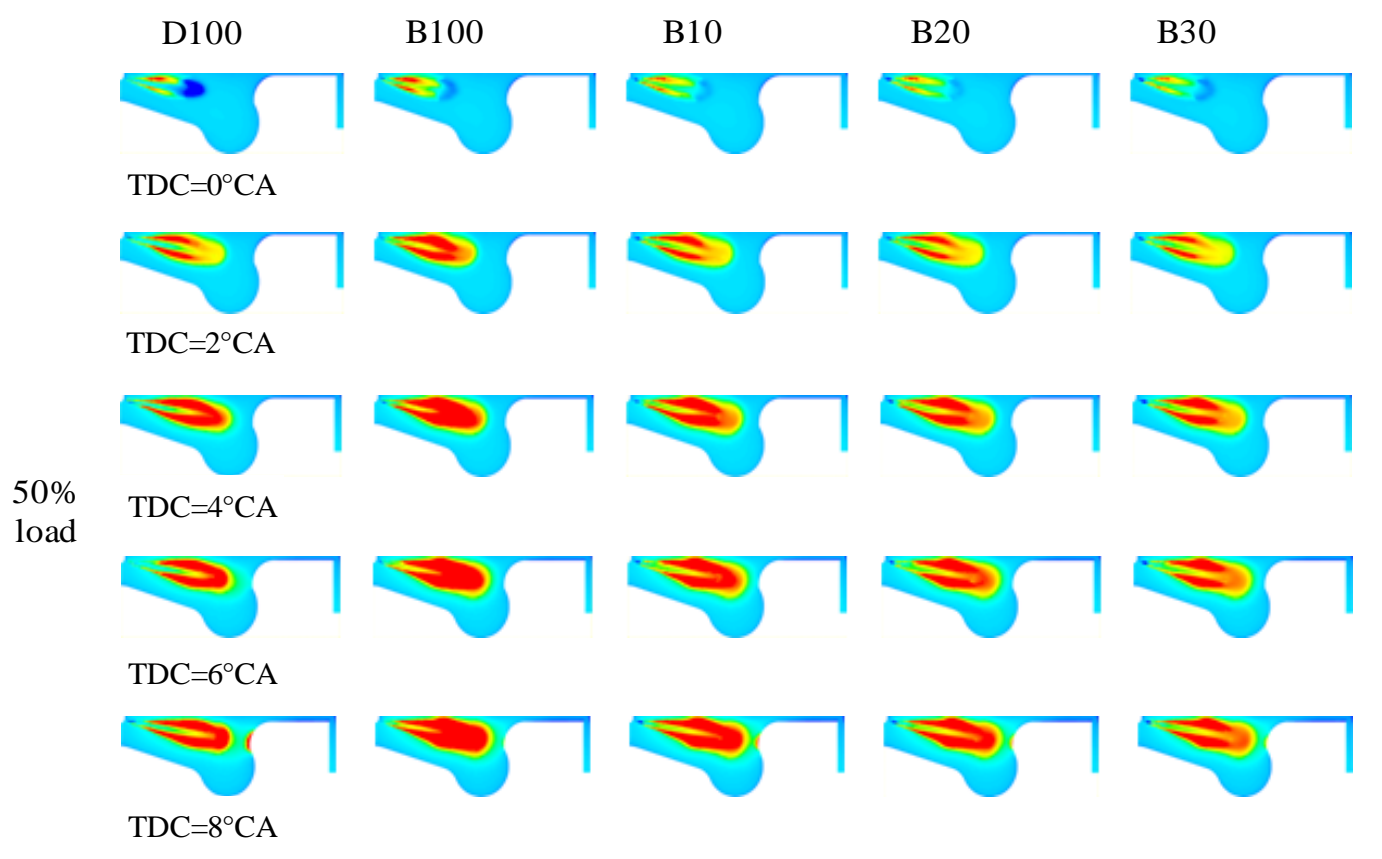

Flow:Temperature[K]
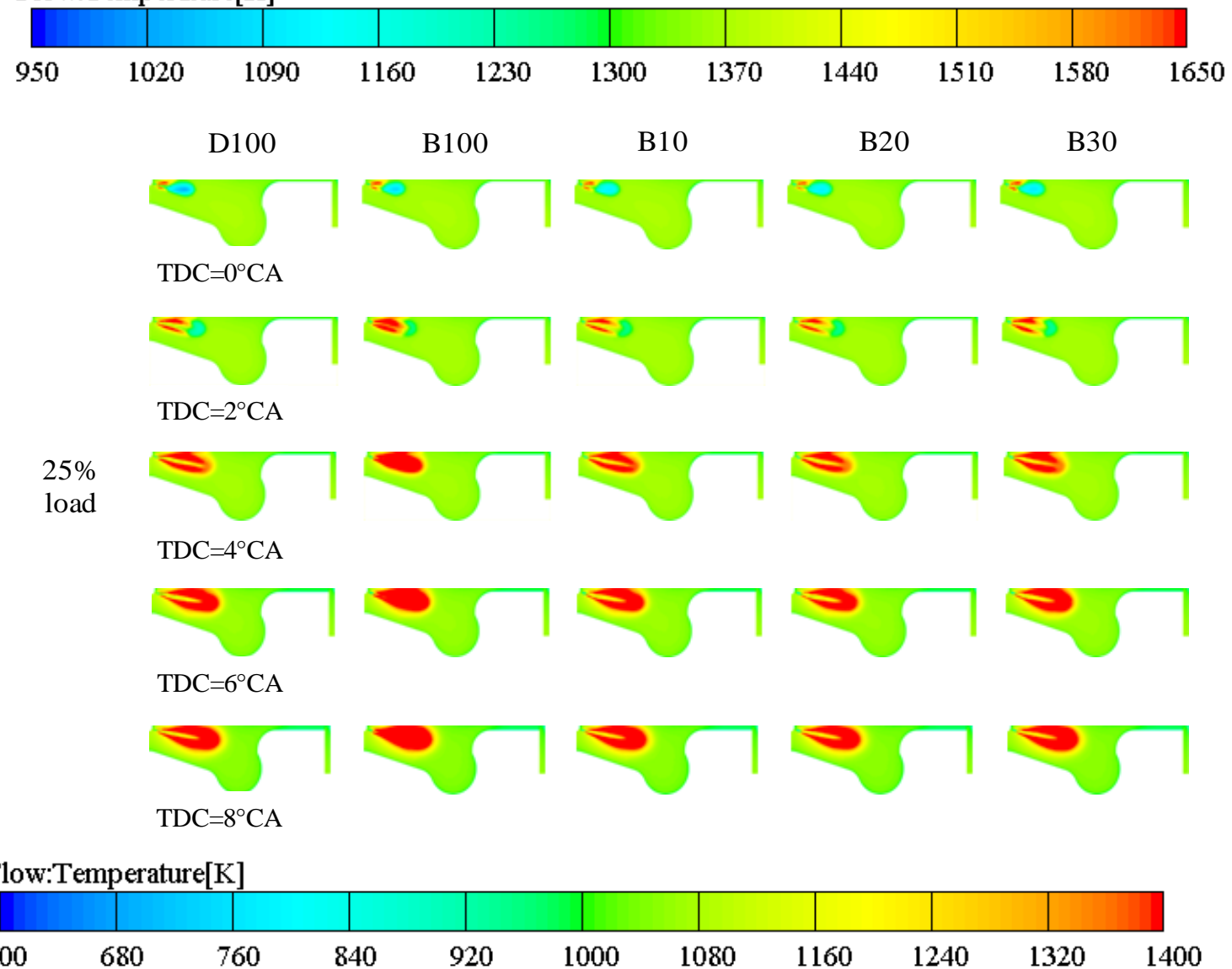

Figure 9. In-cylinder temperature distribution field at different loads.

\subsubsection{Brake Specific Fuel Consumption}

The BSFC is an important parameter in the evaluation of the diesel engine. Figure 10 shows the BSFCs at different loads. It can be found that the BSFC increases with the increase in the biodiesel mixing ratio. For example, the BSFC of B100 is $365.77 \mathrm{~g} /(\mathrm{kW} \cdot \mathrm{h})$ 
at the low load. Compared with D100, the BSFC of B100 increases by $13 \%$ at low load. However, the BSFCs of B10, B20 and B30 increases by $1.1 \%, 2.3 \%$ and $3.3 \%$, respectively, compared with that of D100. This result is due to the low calorific value of biodiesel [47]. At low load, the high viscosity is not beneficial to the fuel spray. While the engine load increases, the oxygen content in biodiesel improves the combustion in the cylinder [48], thus reducing the negative effects of the low calorific value.

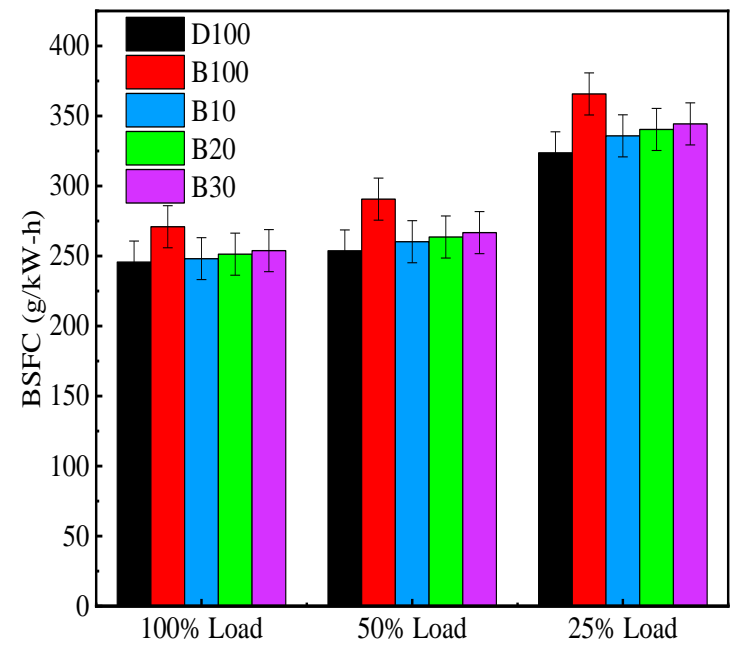

Figure 10. The effects of biodiesel rate on BSFC at different loads.

\subsubsection{Brake Thermal Efficiency}

The brake thermal efficiency (BTE) is the rate energy [47]. It can be calculated by the following equation:

$$
\eta_{i t}=\frac{3600}{B H_{u}}
$$

where $H_{u}$ is low calorific value, $\mathrm{MJ} \cdot \mathrm{kg}^{-1} ; B$ is brake specific fuel consumption, $\mathrm{g} /(\mathrm{kW} \cdot \mathrm{h})$.

Figure 11 shows the BTEs of diesel-biodiesels with different biodiesel mixing ratios at different loads. It can be found that the BTEs of B100, B10, B20, and B30 were decreased by $5.9 \%, 2.95 \%, 3.5$ and $3.65 \%$, respectively, compared with that of pure diesel at low load. However, the BTEs of B100, B10, B20, and B30 were decreased by $2.53 \%, 0.32 \%, 0.87 \%$, and $1.19 \%$, respectively, compared with that of pure diesel at high load. This result is due to the lower calorific value and higher viscosity of biodiesel [49]. When the engine load increases, the spray character is improved by the increase of cylinder temperature, then the cylinder combustion is improved [50]. Thus, the BTEs of B100, B10, B20, and B30 are improved.

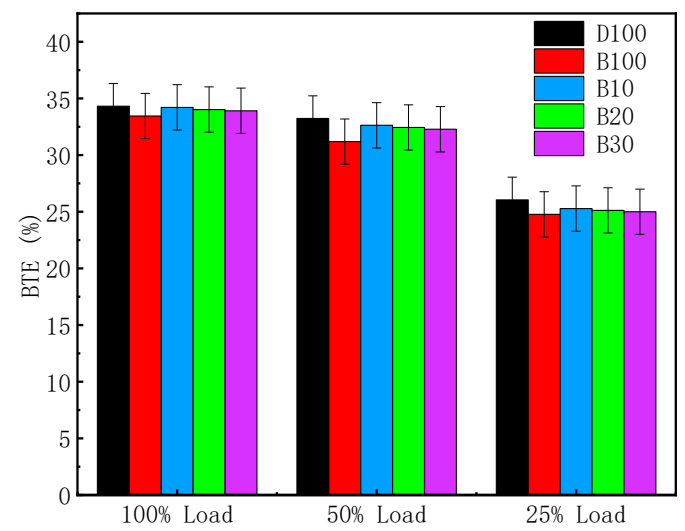

Figure 11. The effects of biodiesel rate on BTE at different loads. 


\subsection{Emission Characteristics}

\subsubsection{Carbon Monoxide Emission}

Carbon monoxide (CO) is a poisonous gas that is colorless and odorless [51]. Incomplete hydrocarbon fuel combustion will lead to the formation of carbon monoxide [52]. Figure 12a-c shows the $\mathrm{CO}$ emissions with different biodiesel mixing ratios at different loads. It can be found that with more fuel, more $\mathrm{CO}$ will be generated with the increase in load. However, the greater the load, the faster the oxidation rate of $\mathrm{CO}$. In addition, the $\mathrm{CO}$ formation can be restrained, hence the $\mathrm{CO}$ emission can be decreased with the increased biodiesel mixing ratio and cylinder temperature. This is due to the oxygen content of biodiesel. More specifically, the CO emission of B100 is reduced by $68.8 \%$ compared with that of D100 at $100 \%$ load. In addition, the CO emission of B100 is reduced by $24.6 \%$ compared with that of D100 at 25\% load. This is due to the fact that the high viscosity of biodiesel is not beneficial to the oxidation of carbon monoxide.
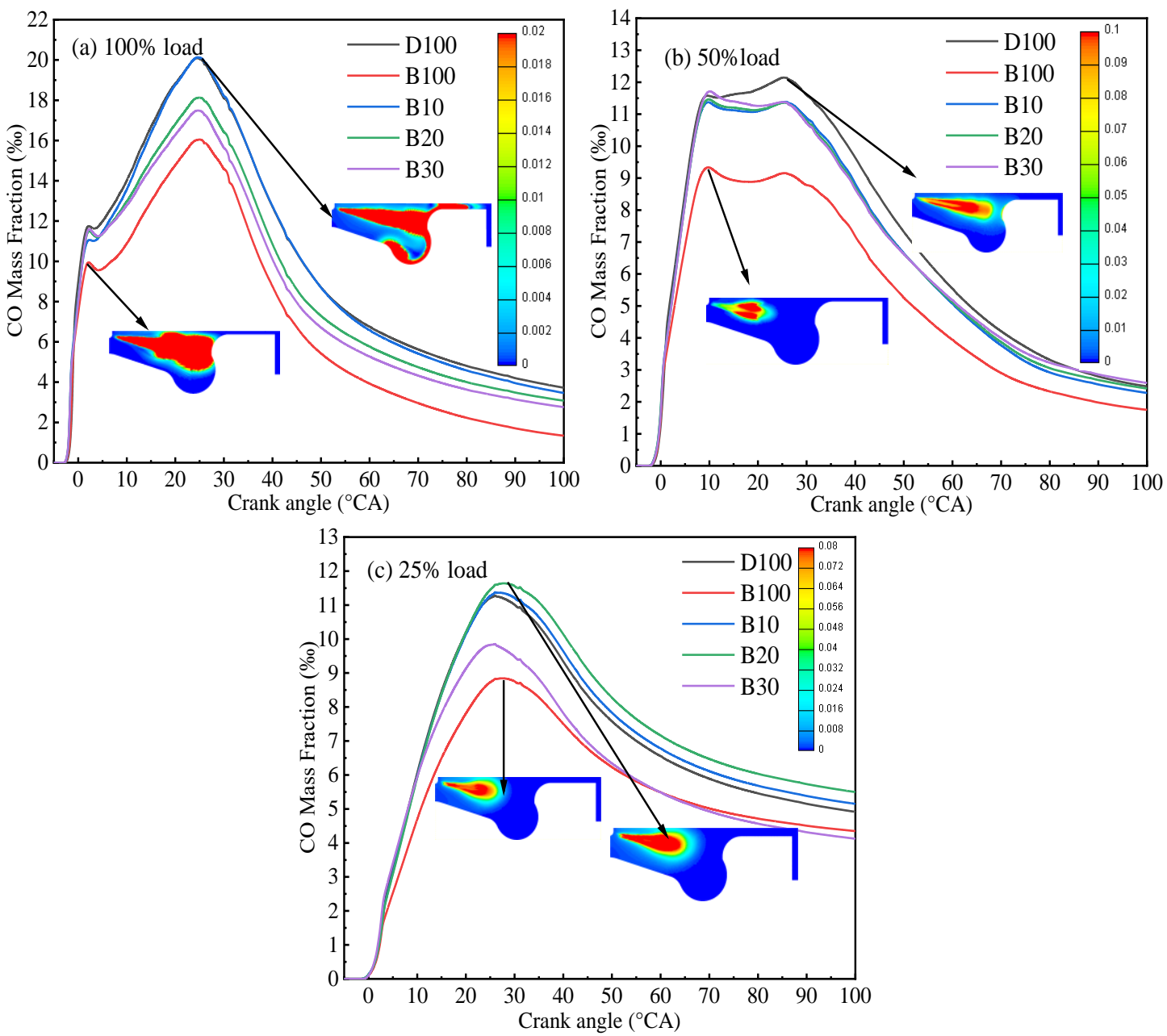

Figure 12. Effects of different biodiesel rates on CO emissions at different loads: (a) CO mass fraction at $100 \%$ load; (b) CO mass fraction at 50\% load; (c) CO mass fraction at $25 \%$ load.

\subsubsection{Nitrogen Oxide Emission}

Figure 13 shows the $\mathrm{NO}_{\mathrm{x}}$ emissions with different biodiesel mixing ratios at different loads. It can be found that the $\mathrm{NO}_{\mathrm{x}}$ emission will increase with the increase in biodiesel mixing ratios at different loads. Specifically, the $\mathrm{NO}_{x}$ emission of $\mathrm{B} 100$ is about $45.21 \%$ higher than pure diesel at low load. In addition, compared with D100 at low load, the $\mathrm{NO}_{\mathrm{x}}$ emissions of $\mathrm{B} 10, \mathrm{~B} 20$, and $\mathrm{B} 30$ increased by $8.62 \%, 17.63 \%$, and $26.64 \%$, respectively. With the increase in load, $\mathrm{NO}_{\mathrm{x}}$ emission differences between D100 and B100 gradually 
decreased. The same results could also be found in Reference [53]. Thus, the biodiesel will result in more $\mathrm{NO}_{\mathrm{x}}$ emission, due to the higher oxygen content in the biodiesel.

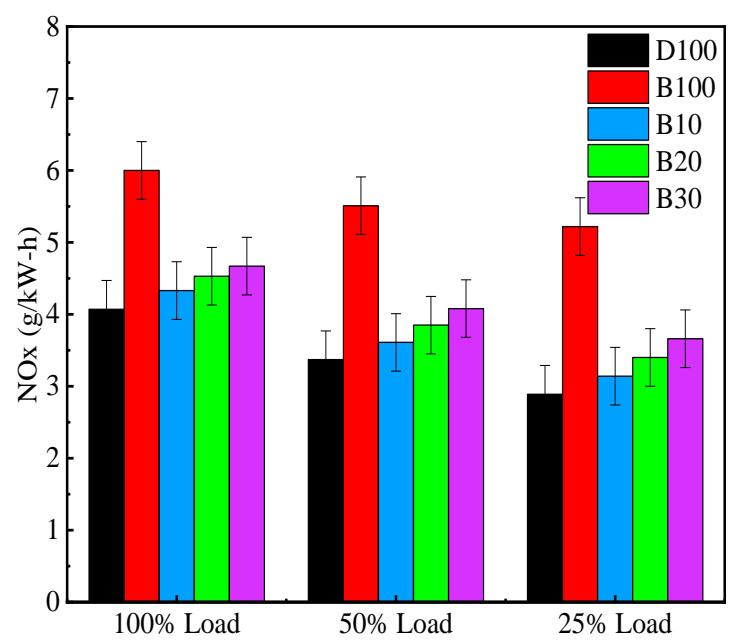

Figure 13. The effects of biodiesel rate on NOx emissions at different loads.

\subsubsection{Soot Emission}

Figure 14 shows the soot emission with different biodiesel mixing ratios at different loads. It can be found that the emission of soot decreases continuously with the increase in mixing ratio. In addition, the greater the load, the greater the effect of the biodiesel mixing ratio. Specifically, the soot emission of B100 is reduced by $41.62 \%$ compared with that of D100 at 100\% load. Similarly, compared with D100, the soot emissions of B10, B20, and B30 are reduced by $4.86 \%, 8.20 \%$, and $14.59 \%$, respectively at $100 \%$ load. This is due to the higher oxygen content in the biodiesel. Thus, the biodiesel-diesel fuel improves the combustion in the cylinder. In addition, Figure 15 shows the soot emission distribution fields at different loads. It can be found that the formation of soot emissions is mainly concentrated in the area with high fuel concentration. Therefore, it is easier to produce soot in poor oxygen combustion.

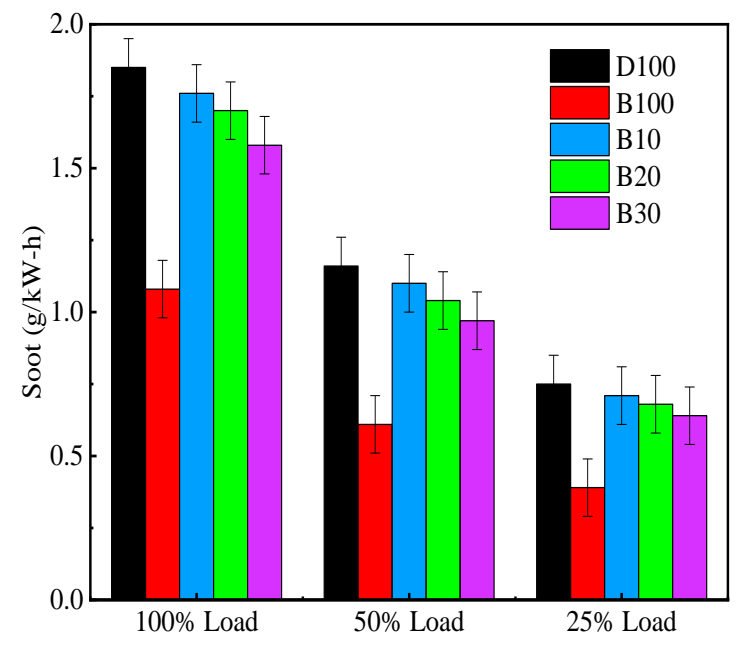

Figure 14. The effects of biodiesel rates on soot emission at different loads. 
$\begin{array}{lllll}\text { D100 } & \text { B100 } & \text { B10 } & \text { B20 } & \text { B30 }\end{array}$

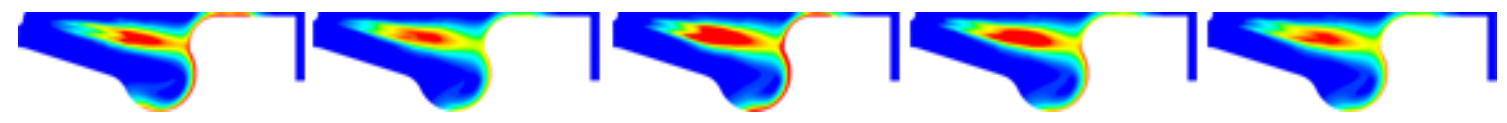

$\mathrm{TDC}=4^{\circ} \mathrm{CA}$

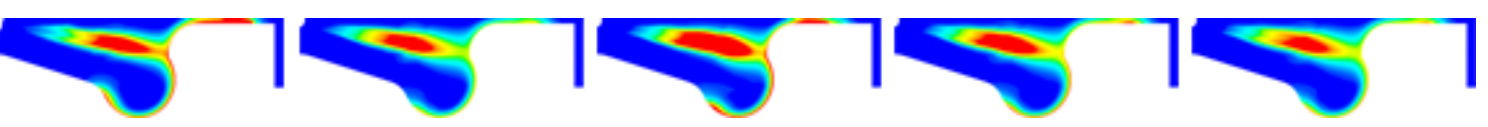

$100 \% \quad \mathrm{TDC}=6^{\circ} \mathrm{CA}$

load
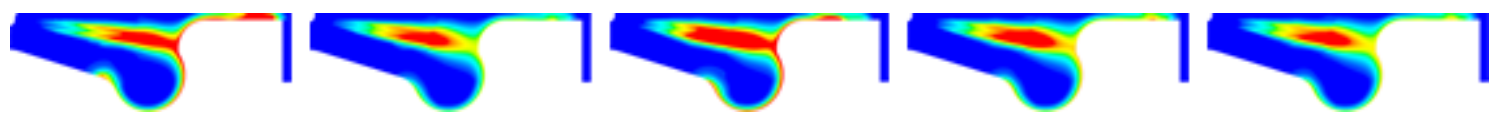

$\mathrm{TDC}=8^{\circ} \mathrm{CA}$
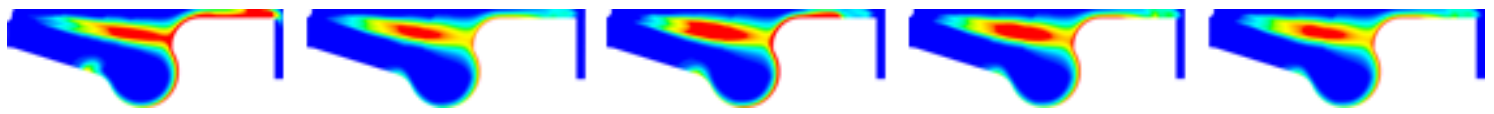

$\mathrm{TDC}=10^{\circ} \mathrm{CA}$

Emission:Soot_Mass_Fraction[-]

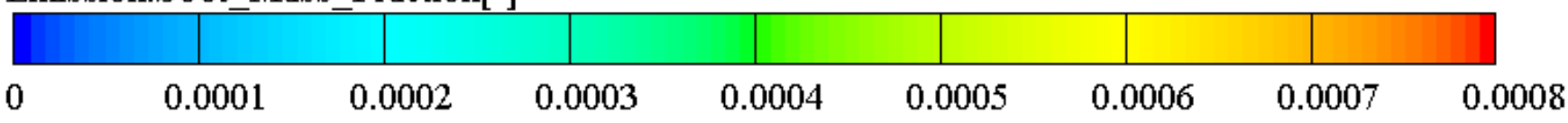

Figure 15. The soot distribution field in the cylinder.

\subsubsection{Hydrocarbon Emission}

Figure 16 shows the hydrocarbon (HC) emission with different biodiesel mixing ratios at different loads. It can be found that the $\mathrm{HC}$ emission decreases with the increase in biodiesel mixing ratio. More specifically, the HC emission of B100 is reduced by $21.62 \%$ compared with that of D100 at 100\% load. Similarly, compared with D100, the soot emissions of B10, B20, and B30 are reduced by $5.18 \%, 8.01 \%$, and $9.18 \%$, respectively, at $100 \%$ load. This result is due to the higher oxygen content in the biodiesel. Thus, the biodiesel-diesel fuel improves the combustion in the cylinder.

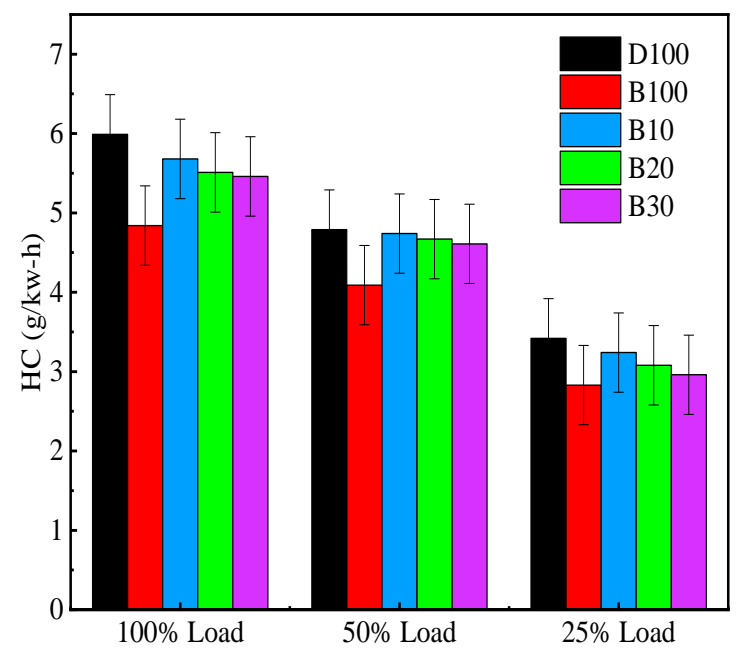

Figure 16. Effect of different biodiesel rates on HC emission at different loads. 


\section{Conclusions}

To overcome the energy crisis [54-62] and and environmental problems [63-69], it is necessary to study biodiesel [70-72]. In this paper, a diesel engine model was developed by AVL-Fire. Then, the model verified by experimental results is employed to investigate the combustion and emission of diesel engine fuel with diesel-biodiesel fuel at different loads. Based on the above analysis, the main conclusions are as follows:

(1) The maximum cylinder pressure is reduced with the increase in biodiesel mixing ratios. The cylinder pressures of B100, B30, B20 and B10 are decreased by $4.69 \%$, $3.62 \%, 3.52 \%$, and $3.25 \%$, respectively, compared with that of D100 at low load. When the engine load increases, the spray character is improved by the increase of cylinder temperature. Thus, the difference of cylinder pressure is reduced.

(2) The longer ignition delay is beneficial to the physical evaporation and mixing process of air and fuel. The physical ignition delay has the greatest impact on ignition character. The D100 shows the earliest ignition delay in all cases, followed by B10, B20 and B10. In addition, the BSFC increases with the increase in biodiesel mixing ratio. The BSFCs of $\mathrm{B} 10, \mathrm{~B} 20$ and $\mathrm{B} 30$ increases by $1.1 \%, 2.3 \%$ and $3.3 \%$, respectively, compared with that of D100.

(3) The $\mathrm{NO}_{x}$ emission will increase with the increase in biodiesel mixing ratios at different loads. Compared with D100 at low load, the $\mathrm{NO}_{\mathrm{x}}$ emissions of B10, B20, and B30 increased by $8.62 \%, 17.63 \%$, and $26.64 \%$, respectively. With the increase in load, $\mathrm{NO}_{\mathrm{x}}$ emission differences between D100 and B100 gradually decreased.

(4) Compared with diesel fuel, biodiesel can significantly reduce the emissions of $\mathrm{CO}$, $\mathrm{HC}$ and soot and no significant change has been found in engine performance.

Author Contributions: Conceptualization, D.T., Z.Z. and D.Y.; software, Y.Z. (Yanhui Zhang) and Y.Z. (Yunhao Zhong); formal analysis, Y.Z. (Yanhui Zhang), D.T. and Z.Z.; investigation, Y.Z. (Yanhui Zhang), Y.Z. (Yunhao Zhong) and D.Y.; resources, D.T., Z.Z. and D.Y.; writing-original draft preparation, Y.Z. (Yanhui Zhang), Y.Z. (Yunhao Zhong), J.W. and D.Y.; writing-review and editing, Y.Z. (Yanhui Zhang), Z.Z. and D.Y.; supervision, D.T., Z.Z. and D.Y.; funding acquisition, Z.Z. and D.Y. All authors have read and agreed to the published version of the manuscript.

Funding: This research is supported by the Guangxi University of Science and Technology Doctoral Fund under the research grants of 20Z22, $20 \mathrm{S04}$ and 21Z34; the work is supported by the Science and Technology Project of Liuzhou under the research grants of 2019DH10601; the work is supported by the Science and Technology Project of Guangxi under the research grants of GK AD19245149; the work is supported by the National Natural Science Foundation of China (No. 52165055).

Institutional Review Board Statement: Not applicable.

Informed Consent Statement: Not applicable.

Data Availability Statement: All data used to support the findings of this study are included within the article.

Conflicts of Interest: The authors declare no conflict of interest.

\section{References}

1. Wallington, T.J.; Lambert, C.K.; Ruona, W.C. Diesel vehicles and sustainable mobility in the U.S. Energy Policy $2013,54,47-53$. [CrossRef]

2. Masoudi, N.; Zaccour, G. Adapting to climate change: Is cooperation good for the environment? Econ. Lett. 2017, 153, 1-5. [CrossRef]

3. Ong, H.C.; Mahlia, T.M.I.; Masjuki, H.H. A review on energy scenario and sustainable energy in Malaysia. Renew. Sustain. Energy Rev. 2011, 151, 639-647. [CrossRef]

4. Lin, L.; Cun, Z.; Vittayapadung, S.; Xiang, S.; Ming, D. Opportunities and challenges for biodiesel fuel. Appl. Energy 2011, 88, 1020-1031. [CrossRef]

5. Zhang, Z.; Jiaqiang, E.; Chen, J.; Zhao, X.; Zhang, B.; Deng, Y.; Peng, Q.; Yin, Z. Effects of boiling heat transfer on the performance enhancement of a medium speed diesel engine fueled with diesel and rapeseed methyl ester. Appl. Therm. Eng. 2020, 169, 114984. [CrossRef] 
6. Jiaqiang, E.; Zhang, Z.; Chen, J.; Pham, M.; Zhao, X.; Peng, Q.; Zhang, B.; Yin, Z. Performance and emission evaluation of a marine diesel engine fueled by water biodiesel-diesel emulsion blends with a fuel additive of a cerium oxide nanoparticle. Energy Convers. Manag. 2018, 169, 194-205.

7. Zhang, Z.; Jiaqiang, E.; Deng, Y.; Pham, M.; Zuo, W.; Peng, Q.; Yin, Z. Effects of fatty acid methyl esters proportion on combustion and emission characteristics of a biodiesel fueled marine diesel engine. Energy Convers. Manag. 2018, 159, 244-253. [CrossRef]

8. Huang, J.; Xiao, H.; Yang, X.; Guo, F.; Hu, X. Effects of methanol blending on combustion characteristics and various emissions of a diesel engine fueled with soybean biodiesel. Fuel 2020, 282, 118734. [CrossRef]

9. Zhang, Z.; YJiaqiang, E.; Tan, D.; Feng, Z.; Luo, J.; Tan, Y.; Huang, Y. The effects of $\mathrm{Fe}_{2} \mathrm{O}_{3}$ based DOC and SCR catalyst on the combustion and emission characteristics of a diesel engine fueled with biodiesel. Fuel 2021, 290, 120039. [CrossRef]

10. Çelik, M.; Bayindirli, C. Enhancement performance and exhaust emissions of rapeseed methyl ester by using n-hexadecane and n-hexane fuel additives. Energy 2020, 202, 117643. [CrossRef]

11. Zhang, Z.; Jiaqiang, E.; Chen, J.; Zhu, H.; Zhao, X.; Han, D.; Zuo, W.; Peng, Q.; Gong, J.; Yin, Z. Effects of low-level water addition on spray, combustion and emission characteristics of a medium speed diesel engine fueled with biodiesel fuel. Fuel 2019, 239, 245-262. [CrossRef]

12. Li, W.; Ji, J.; Huang, L.; Guo, Z. Global dynamics of a controlled discontinuous diffusive SIR epidemic system. Appl. Math. Lett. 2021, 121, 107420. [CrossRef]

13. Tan, D.; Chen, Z.; Li, J.; Luo, J.; Yang, D.; Cui, S.; Zhang, Z. Effects of Swirl and Boiling Heat Transfer on the Performance Enhancement and Emission Reduction for a Medium Diesel Engine Fueled with Biodiesel. Processes 2021, 9, 568. [CrossRef]

14. Liu, T.; Jiaqiang, E.; Yang, W.M.; Deng, Y.; An, H.; Zhang, Z.; Pham, M. Investigation on the applicability for reaction rates adjustment of the optimized biodiesel skeletal mechanism. Energy 2018, 150, 1031-1038. [CrossRef]

15. Rajak, U.; Nashine, P.; Singh, T.S.; Verma, T.N. Numer ical investigation of performance, combustion and emission characteristics of various biofuels. Energy Convers. Manag. 2018, 156, 235-252. [CrossRef]

16. Amini Niaki, S.R.; Mahdavi, S.; Mouallem, J. Experimental and simulation investigation of effect of biodiesel-diesel blend on performance, combustion, and emission characteristics of a diesel engine. Environ. Prog. Sustain. Energy 2018, 37, 1540-1550. [CrossRef]

17. D'Agosto, M.d.A.; da Silva, M.A.V.; Franca, L.S.; de Oliveira, C.M.; Alexandre, M.O.L.; da Costa Marques, L.G.; Murta, A.L.S.; de Freitas, M.A.V. Comparative study of emissions from stationary engines using biodiesel made from soybean oil, palm oil and waste frying oil. Renew. Sustain. Energy Rev. 2017, 70, 1376-1392. [CrossRef]

18. Gokalp, B.; Buyukkaya, E.; Soyhan, H.S. Performance and emissions of diesel tractor engine fueled with marine diesel and soybean methyl ester. Biomass Bioenergy 2011, 35, 3575-3583. [CrossRef]

19. Karavalakis, G.; Johnson, K.C.; Hajbabaei, M.; Durbin, T.D. Application of low-level biodiesel blends on heavy-duty (diesel) engines: Feedstock implications on $\mathrm{NO}_{x}$ and particulate emissions. Fuel 2016, 181, 259-268. [CrossRef]

20. Seraç, M.R.; Aydin, S.; Yilmaz, A.; Sevik, S. Evaluation of comparative combustion, performance, and emission of soybean-based alternative biodiesel fuel blends in a CI engine. Renew. Energy 2020, 148, 1065-1073. [CrossRef]

21. Ahmed, S.A.; Zhou, S.; Zhu, Y.; Feng, Y.; Malik, A.; Ahmad, N. Influence of Injection Timing on Performance and Exhaust Emission of CI Engine Fuelled with Butanol-Diesel Using a 1D GT-Power Model. Processes 2019, 7, 299. [CrossRef]

22. Jiaqiang, E.; Zhao, X.; Qiu, L.; Wei, K.; Zhang, Z.; Deng, Y.; Han, D.; Liu, G. Experimental investigation on performance and economy characteristics of a diesel engine with variable nozzle turbocharger and its application in urban bus. Energy Convers. Manag. 2019, 193, 149-161. [CrossRef]

23. An, H.; Yang, W.M.; Li, J. Effects of ethanol addition on biodiesel combustion: A modeling study. Appl. Energy 2015, 143, 176-188. [CrossRef]

24. An, H.; Yang, W.M.; Chou, S.K.; Chua, K.J. Combustion and emissions characteristics of diesel engine fueled by biodiesel at partial load conditions. Appl. Energy 2012, 99, 363-371. [CrossRef]

25. Lešnik, L.; Vajda, B.; Žunič, Z.; Škerget, L.; Kegl, B. The influence of biodiesel fuel on injection characteristics, diesel engine performance, and emission formation. Appl. Energy 2013, 111, 558-570. [CrossRef]

26. Zhou, D.Z.; Yang, W.M.; An, H.; Li, J.; Shu, C. A numerical study on RCCI engine fueled by biodiesel/methanol. Energy Convers. Manag. 2015, 89, 798-807. [CrossRef]

27. Karami, R.; Rasul, M.G.; Khan, M.M.K.; Mahdi Salahi, M.; Anwar, M. Experimental and computational analysis of combustion characteristics of a diesel engine fueled with diesel-tomato seed oil biodiesel blends. Fuel 2021, 285, 119243. [CrossRef]

28. Zhang, Z.; Li, J.; Tian, J.; Xie, G.; Tan, D.; Qin, B.; Huang, Y.; Cui, S. Effects of Different Diesel-Ethanol Dual Fuel Ratio on Performance and Emission Characteristics of Diesel Engine. Processes 2021, 9, 1135. [CrossRef]

29. Asadi, A.; Zhang, Y.; Mohammadi, H.; Khorand, H.; Rui, Z.; Doranehgard, M.H.; Bozorg, M.V. Combustion and emission characteristics of biomass derived biofuel, premixed in a diesel engine: A CFD study. Renew. Energy 2019, 138, 79-89. [CrossRef]

30. Tutak, W.; Jamrozik, A. Validation and optimization of the thermal cycle for a diesel engine by computational fluid dynamics modeling. Appl. Math. Model. 2016, 40, 6293-6309. [CrossRef]

31. Jiaqiang, E.; Liu, G.; Zhang, Z.; Han, D.; Chen, J.; Wei, K.; Gong, J.; Yin, Z. Effect analysis on cold starting performance enhancement of a diesel engine fueled with biodiesel fuel based on an improved thermodynamic model. Appl. Energy 2019, $243,321-335$. 
32. Jurić, F.; Petranović, Z.; Vujanović, M.; Katrašnik, T.; Vihar, R.; Wang, X.; Duić, N. Experimental and numerical investigation of injection timing and rail pressure impact on combustion characteristics of a diesel engine. Energy Convers. Manag. 2019, 185, 730-739. [CrossRef]

33. Jiang, X.; Siamas, G.A.; Jagus, K.; Karayiannis, T.G. Physical modeling and advanced simulations of gas-liquid two-phase jet flows in atomization and sprays. Prog. Energy Combust. Sci. 2010, 36, 131-167. [CrossRef]

34. Anvari, S.; Taghavifar, H.; Khalilarya, S.; Jafarmadar, S.; Shervani-Tabar, M.T. Numerical simulation of diesel injector nozzle flow and in-cylinder spray evolution. Appl. Math. Model. 2016, 40, 8617-8629. [CrossRef]

35. Luo, J.; Liu, Z.; Wang, J.; Chen, H.; Zhang, Z.; Qin, B.; Cui, S. Effects of Different Injection Strategies on Combustion and Emission Characteristics of Diesel Engine Fueled with Dual Fuel. Processes 2021, 9, 1300. [CrossRef]

36. Petranovic, Z.; Besenic, T.; Vujanovic, M.; Duic, N. Modeling pollutant emissions in diesel engines, influence of biofuel on pollutant formation. J. Environ. Manag. 2017, 203, 1038-1046. [CrossRef]

37. Scheffknecht, G.; Al-Makhadmeh, L.; Schnell, U.; Maier, J. Oxy-fuel coal combustion-A review of the current state-of-the-art. Int. J. Greenh. Gas Control. 2011, 5, S16-S35. [CrossRef]

38. Jurić, F.; Petranović, Z.; Vujanović, M.; Duić, N. Numerical assessment of radiative heat transfer impact on pollutant formation processes in a compression ignition engine. J. Clean. Prod. 2020, 275, 123087. [CrossRef]

39. Temizer, I.; Cihan, Ö.; Eskici, B. Numerical and experimental investigation of the effect of biodiesel/diesel fuel on combustion characteristics in CI engine. Fuel 2020, 270, 117523. [CrossRef]

40. Pereyra-Irujo, G.A.; Izquierdo, N.G.; Covi, M.; Nolasco, S.M.; Quiroz, F.; Aguirrezábal, A.N. Variability in sunflower oil quality for biodiesel production: A simulation study. Biomass Bioenergy 2009, 33, 459-468. [CrossRef]

41. Nabi, M.N.; Rahman, M.M.; Akhter, M.S. Biodiesel from cotton seed oil and its effect on engine performance and exhaust emissions. Appl. Therm. Eng. 2009, 29, 2265-2270. [CrossRef]

42. Ghadikolaei, M.A. Effect of alcohol blend and fumigation on regulated and unregulated emissions of IC engines-A review. Renew. Sustain. Energy Rev. 2016, 57, 1440-1495. [CrossRef]

43. Qi, D.H.; Geng, L.M.; Chen, H.; Bian, Y.Z.; Liu, J.; Ren, X.C. Combustion and performance evaluation of a diesel engine fueled with biodiesel produced from soybean crude oil. Renew. Energy 2009, 34, 2706-2713. [CrossRef]

44. Özener, O.; Yüksek, L.; Ergenç, A.T.; Özkan, M. Effects of soybean biodiesel on a DI diesel engine performance, emission and combustion characteristics. Fuel 2014, 115, 875-883. [CrossRef]

45. Valente, O.S.; da Silva, M.J.; Pasa, V.M.D.; Belchior, C.R.P.; Sodré, J.R. Fuel consumption and emissions from a diesel power generator fuelled with castor oil and soybean biodiesel. Fuel 2010, 89, 3637-3642. [CrossRef]

46. Barrios, C.C.; Domínguez-Sáez, A.; Martín, C.; Álvarez, P. Effects of animal fat based biodiesel on a TDI diesel engine performance, combustion characteristics and particle number and size distribution emissions. Fuel 2014, 117, 618-623. [CrossRef]

47. Çelik, M.; Önder Özgören, Y. The determination of effects of soybean and hazelnut methyl ester addition to the diesel fuel on the engine performance and exhaust emissions. Appl. Therm. Eng. 2017, 124, 124-135. [CrossRef]

48. Al-Dawody, M.F.; Bhatti, S.K. Optimization strategies to reduce the biodiesel NOx effect in diesel engine with experimental verification. Energy Convers. Manag. 2013, 68, 96-104. [CrossRef]

49. Mobasheri, R.; Peng, Z.; Mirsalim, S.M. Analysis the effect of advanced injection strategies on engine performance and pollutant emissions in a heavy duty DI-diesel engine by CFD modeling. Int. J. Heat Fluid Flow 2012, 33, 59-69. [CrossRef]

50. Cai, T.; Zhao, D.; Li, X.; Shi, B.; Li, J. Mitigating NOx emissions from an ammonia-fueled micro-power system with a perforated plate implemented. J. Hazard. Mater. 2021, 401, 123848. [CrossRef]

51. Can, Ö.; Öztürk, E.; Solmaz, H.; Aksoy, F.; Çinar, C.; Yücesu, H.S. Combined effects of soybean biodiesel fuel addition and EGR application on the combustion and exhaust emissions in a diesel engine. Appl. Therm. Eng. 2016, 95, 115-124. [CrossRef]

52. Lu, Y.; Jiang, Z.; Geng, N.; Jiang, S.; Xie, X. Appointment window scheduling with wait-dependent abandonment for elective inpatient admission. Int. J. Prod. Res. 2021, 1-17. [CrossRef]

53. Cai, T.; Zhao, D.; Wang, B.; Li, J.; Guan, Y. NO emission and thermal performances studies on premixed ammonia-oxygen combustion in a $\mathrm{CO}_{2}$-free micro-planar combustor. Fuel 2020, 280, 118554. [CrossRef]

54. Cai, T.; Becker, S.M.; Cao, F.; Wang, B.; Tang, A.; Fu, J.; Han, L.; Sun, Y.; Zhao, D. NO emission performance assessment on a perforated plate-implemented premixed ammonia-oxygen micro-combustion system. Chem. Eng. J. 2021, 417, 128033. [CrossRef]

55. Cai, T.; Zhao, D. Effects of fuel composition and wall thermal conductivity on thermal and NOx emission performances of an ammonia/hydrogen-oxygen micro-power system. Fuel Process. Technol. 2020, 209, 106527. [CrossRef]

56. Zuo, H.; Tan, J.; Wei, K.; Huang, Z.; Zhong, D.; Xie, F. Effects of different poses and wind speeds on wind-induced vibration characteristics of a dish solar concentrator system. Renew. Energy 2021, 168, 1308-1326. [CrossRef]

57. Zuo, H.; Liu, G.; Jiaqiang, E.; Zuo, W.; Wei, K.; Hu, W.; Tan, J.; Zhong, D. Catastrophic analysis on the stability of a large dish solar thermal power generation system with wind-induced vibration. Sol. Energy 2019, 183, 40-49. [CrossRef]

58. Hu, L.; Hu, X.; Che, Y.; Feng, F.; Lin, X.; Zhang, Z. Reliable state of charge estimation of battery packs using fuzzy adaptive federated filtering. Appl. Energy 2020, 262, 114569. [CrossRef]

59. Zuo, H.; Zhang, B.; Huang, Z.; Wei, K.; Tan, J. Effect analysis on SOC values of the power lithium manganate battery during discharging process and its intelligent estimation. Energy 2022, 238, 121854. [CrossRef]

60. Jiaqiang, E.; Zhang, B.; Zeng, Y.; Wen, M.; Huang, Z.; Wei, K.; Chen, J.; Zhu, H.; Deng, Y. Effects analysis on active equalization control of lithium-ion batteries based on intelligent estimation of the state-of-charge. Energy 2022, 238, 121822. [CrossRef] 
61. Jiaqiang, E.; Luo, B.; Han, D.; Chen, J.; Liao, G.; Zhang, F.; Ding, J. A comprehensive review on performance improvement of micro energy mechanical system: Heat transfer, micro combustion and energy conversion. Energy 2022, 240, 122509. [CrossRef]

62. Yi, F.; Jiaqiang, E.; Zhang, B.; Zuo, H.; Wei, K.; Chen, J.; Zhu, H.; Zhu, H.; Deng, Y. Effects of coupling phase change material and liquid cooling on heat dissipation characteristics of Lithium-ion battery thermal management system. Renew. Energy 2022, 181, 472-489. [CrossRef]

63. Jiaqiang, E.; Zhao, M.; Zuo, Q.; Zhang, B.; Zhang, Z.; Peng, Q.; Han, D.; Zhao, X.; Deng, Y. Effects analysis on diesel soot continuous regeneration performance of a rotary microwave-assisted regeneration diesel particulate filter. Fuel 2020, 260, 116353. [CrossRef]

64. Feng, C.; Deng, Y.; Chen, L.; Han, W.; Jiaqiang, E.; Wei, K.; Han, D.; Zhang, B. Hydrocarbon emission control of a hydrocarbon adsorber and converter under cold start of the gasoline engine. Energy 2022, 239. [CrossRef]

65. Chen, L.; Deng, Y.; Feng, C.; Han, W.; Jiaqiang, E.; Wang, C.; Han, D.; Zhang, B. Effects of zeolite molecular sieve on the hydrocarbon adsorbent performance of gasoline engine of during cold start. Fuel 2022, 310. [CrossRef]

66. Jiaqiang, E.; Luo, J.; Han, D.; Tan, Y.; Feng, C.; Deng, Y. Effects of different catalysts on light-off temperature of volatile organic components in the rotary diesel particulate filter during the regeneration. Fuel 2022, 310. [CrossRef]

67. Zhang, B.; Zuo, H.; Huang, Z.; Tan, J.; Zuo, Q. Endpoint forecast of different diesel-biodiesel soot filtration process in diesel particulate filters considering ash deposition. Fuel 2020, 272, 117678. [CrossRef]

68. Zhang, B.; Jiaqiang, E.; Gong, J.; Yuan, W.; Zuo, W.; Li, Y.; Fu, J. Multidisciplinary design optimization of the diesel particulate filter in the composite regeneration process. Appl. Energy 2016, 181, 14-28. [CrossRef]

69. Zuo, Q.; Xie, Y.; Jiaqiang, E.; Zhu, X.; Zhang, B.; Tang, Y.; Zhu, G.; Wang, Z.; Zhang, J. Effect of different exhaust parameters on NO conversion efficiency enhancement of a dual-carrier catalytic converter in the gasoline engine. Energy 2020, $191,116521$. [CrossRef]

70. Gangolu, N.R.; Chunchu, B.R.K.; Yallamati, A.; Gopidesi, R.K. Assessment of diesel engine characteristics by using soybean oil as a biofuel. Environ. Dev. Sustain. 2021, 21, 1645.

71. Jiaqiang, E.; Pham, M.; Zhao, D.; Deng, Y.; Le, D.; Zuo, W.; Zhu, H.; Liu, T.; Peng, Q.; Zhang, Z. Effect of different technologies on combustion and emissions of the diesel engine fueled with biodiesel: A review. Renew. Sustain. Energy Rev. 2017, 80, 620-647. [CrossRef]

72. Wu, G.; Wang, X.; Abubakar, S.; Li, Y.; Liu, Z. A realistic skeletal mechanism for the oxidation of biodiesel surrogate composed of long carbon chain and polyunsaturated compounds. Fuel 2021, 289, 119934. [CrossRef] 